\title{
THE FUNCTIONS OF STRUCTURE AND DYNAMICS IN PROTEINS, PEPTIDES AND METAL ION COMPLEXES AND THEIR RELATIONSHIPS TO BIOLOGICAL RECOGNITION AND THE HANDLING OF INFORMATION
}

\author{
by \\ ROBERT J.P. WILLIAMS \\ Department of Inorganic Chemistry, \\ University of Oxford, Oxford, England \\ Presented as the 8th Linderstrøm-Lang Lecture \\ at the Carlsberg Laboratory, Copenhagen, on 28th November, 1986
}

Keywords: Protein conformations, protein mobility, metallo-enzymes, triggers, transmitters, hormones, calcium, zinc, helices, $\beta$-sheets, transmission of information, molecular recognition, molecular machines

\section{CONTENTS}

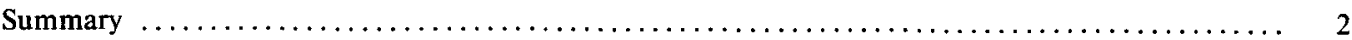

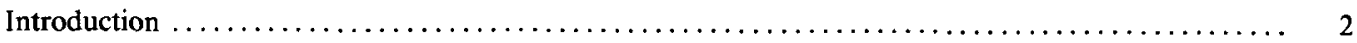

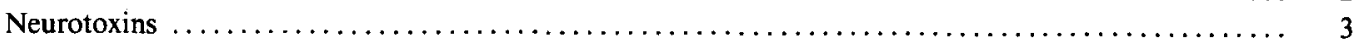

The Kringle Dynamic Structure $\ldots \ldots \ldots \ldots \ldots \ldots \ldots \ldots \ldots \ldots \ldots \ldots \ldots \ldots \ldots \ldots \ldots \ldots \ldots \ldots \ldots \ldots \ldots, 7$

Hormonal and Transmitter Peptides $\ldots \ldots \ldots \ldots \ldots \ldots \ldots \ldots \ldots \ldots \ldots \ldots \ldots \ldots \ldots \ldots \ldots \ldots \ldots \ldots \ldots$

Antigenic Peptides $\ldots \ldots \ldots \ldots \ldots \ldots \ldots \ldots \ldots \ldots \ldots \ldots \ldots \ldots \ldots \ldots \ldots \ldots \ldots \ldots \ldots \ldots \ldots \ldots \ldots 11$

Small Molecule Hormones and Transmitters $\ldots \ldots \ldots \ldots \ldots \ldots \ldots \ldots \ldots \ldots \ldots \ldots \ldots \ldots \ldots \ldots \ldots \ldots \ldots 12$

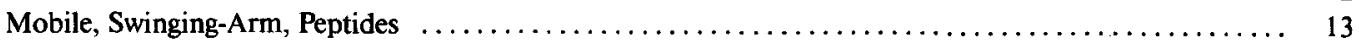

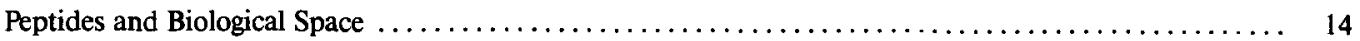

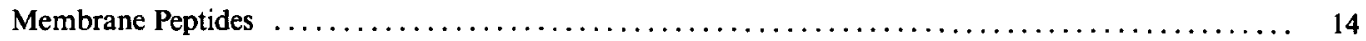

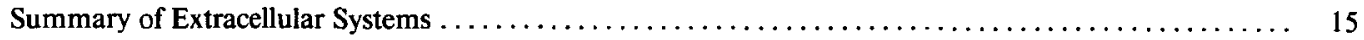

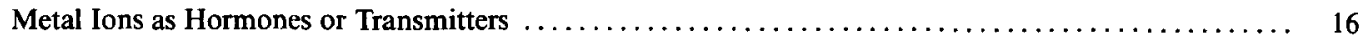

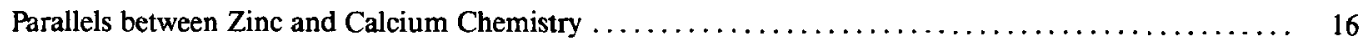

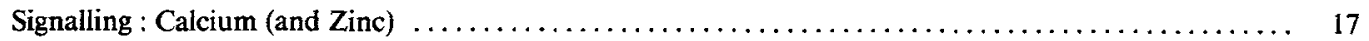

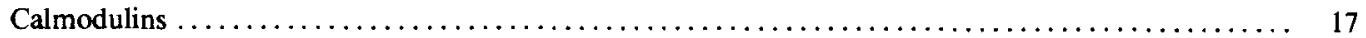

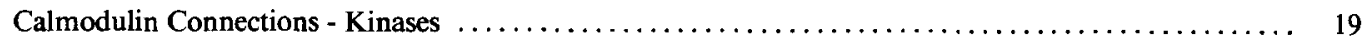

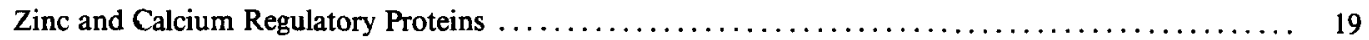

Slower Metal Ion Control $\ldots \ldots \ldots \ldots \ldots \ldots \ldots \ldots \ldots \ldots \ldots \ldots \ldots \ldots \ldots \ldots \ldots \ldots \ldots \ldots \ldots \ldots \ldots$

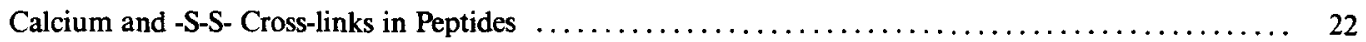

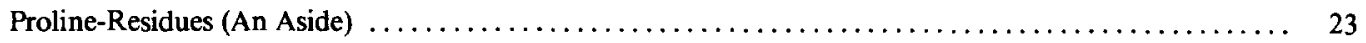

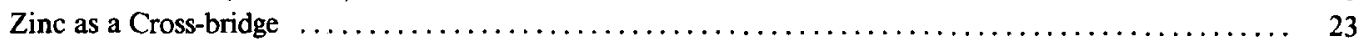

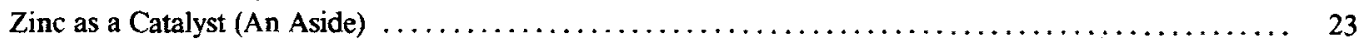

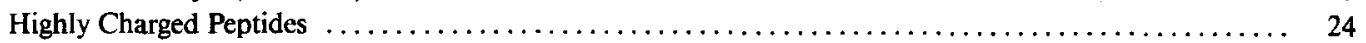

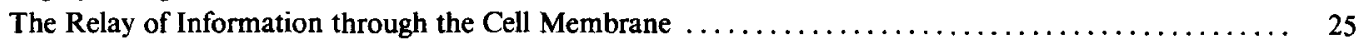

Conclusions:

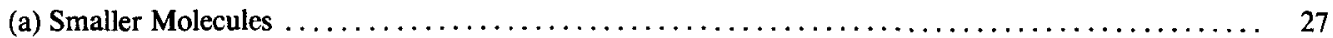

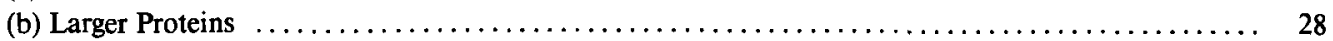

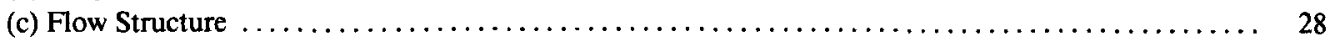

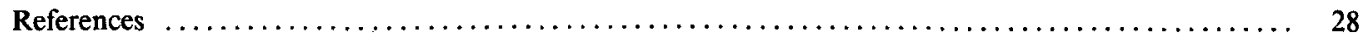


Peptides and proteins, like metal ion complexes, are now known to show a wide variety of dynamic properties. At one extreme are the stable molecules such as neurotoxins. At the other extreme are the random coil hormonal peptides. Amongst metal ion complexes those of calcium are extremely internally mobile while those of nickel are much less so. Biology has put all these dynamics to use in the controls over action. A typical example is the calcium trigger associated with calmodulin.

\section{Introduction}

LINDERSTRøM-LANG (24) considered that proteins in solution were relatively mobile fluctuating structures. His intuition has turned out to be correct in principle but his ability to establish this view-point in the scientific community was limited by the lack of definition of mobility due to the unsuitability of the methods available to him. His major technique of H/D exchange rates was too gross a tool to describe mobility of proteins in a convincing manner. As a consequence his approach was almost forgotten and was certainly overwhelmed by a detailed examination by $\mathrm{X}$-ray diffraction methods of crystalline proteins since these diffraction methods gave structures initially without any apparent need to refer to fluctuations. Even changes of structure were then treated like first order phase transitions between allotropic forms or at melting points. Scientists lost sight of LINDERSTRøMLANG's stress on dynamics. As is often the case in such empirical sciences as chemistry and biology it was new methods, especially nuclear magnetic resonance spectroscopy, which led to a re-assessment of the role of dynamics $(5,14$, $27,37,45,46)$. Today nuclear magnetic resonance techniques have not completely vindicated LINDERSTRØM-LANG's views but have shown their degree of validity. Increasingly, this has been recognised in crystallographic studies too where temperature or B factors are used in analyses $(3,37)$. I shall illustrate this theme by a description of the dynamic structures of some small proteins and peptides since NMR is at its most powerful in the description of molecules of molecular weight below about 10,000 . I shall also connect the theme of dynamics in proteins to dynamics of metal ion coordination spheres and show how biology has evolved to use both in an allodynamic manner (41).
Before tackling individual examples and going on to suggest some general conclusions I need to define "dynamic structure". The word structure is often used in chemistry to describe the disposition in space of atoms independent of time. I shall call this static structure. However, structure is also used in physics to describe the motion of the planets around the sun - "the structure of the solar system". This is a time-dependent definition since the orbits change slightly with time, which I shall call flow structure. Time dependence can also be oscillatory about a mean, rather than continuously evolving, and I shall call this a dynamic structure. The structure of living systems is a flow not an oscillation so that neither X-ray B-factors (very short time scale) nor time constants of NMR (much longer time scale) relate to the flow of life, but only refer to reversible dynamic processes. It is these reversible processes which I shall describe here.

When physicists and chemists work together both static and dynamic ideas of structure tend to merge while describing rotational/vibrational motions in the structure of a molecule. This is the area of the smallest contribution of dynamics to dynamic structure. The methyl group of ethanol constantly rotates, as in all protein structures, and even if we look at $\mathrm{CH}_{2} \mathrm{D} \cdot \mathrm{CH}_{2} \mathrm{OH}$ where we have removed the degeneracy of the $-\mathrm{CH}_{3}$ group we think we know what we mean by its structure - it is a dynamic concept with weighted occupancies of position. In chemistry apart from rotation and vibration about single bonds there are also grosser changes associated with condensed phases which involve translational motion, e.g. on melting. Partial melting is possible in a glass and a polymer such as a structured protein can melt locally, configurational motion, and for a short period of time (5). It is these grosser reversible configurational 
or main chain conformational motions to which I shall refer most. Unfortunately, X-ray diffraction is not at its best as a method for describing these larger scale dynamics of molecules and so simplified static structures have usually been provided by $\mathrm{X}$-ray crystallographers and then used by all of us in efforts to define function in solution. Today it is usual to add rotational/vibrational modes by referring to B-factors, but these are not the most significant part of the dynamics. A real effort of a different kind using different methods has to be made if we are to reach a genuine understanding of peptides and proteins which has to be based on a thorough examination of main chain dynamics so that the gap in the relationship, composition (sequence) $\rightarrow$ dynamic structure $\rightarrow$ function, can be filled. The examples I take next to illustrate my theme are largely from my own work, but I wish to stress particularly the contributions of members of the Oxford Enzyme Group (particularly J. BOYD, I.D. CAMPBELL, C.M. DOBSON, R.A. DWEK, B.A. LeVINe, G.R. Moore, N. Soff, P. Wright and $M$. INAGAKI) and two particular persons from a "rival" research group (R. ERNST and $\mathrm{K}$. Wüthrich, see (4)) to both methods and concepts. Table I lists some NMR approaches to dynamic structure.

\section{Neurotoxins}

The X-ray structures of several neurotoxins in crystals are now known, Figure 1 (20). The study by NMR of these structures showed that the fold is closely maintained in solution $(17,18,19,20)$, and that after correction for minor mistakes in sequences and interpretation of structural data

Table I. Some NMR Approaches to Mobility

(1) Flipping of aromatic residues and of valine or leucine asymmetric tops. Chemical shift (averaging) and line width measurements.

(2) Temperature dependence of chemical shifts.

(3) Coupling constant averaging.

(4) Line widths of resonances ( $T_{2}$ data).

(5) NH/ND exchange of assigned resonances.

(6) cis/trans isomerism of proline (saccharide) rings.

N.B. The nucleus which is used can be any one of several, e.g. ' $\mathrm{H}, \mathrm{D},{ }^{13} \mathrm{C},{ }^{31} \mathrm{P}$ etc. (by both methods) the packing of the internal side-chains is known to be the same in both states. For tightly folded proteins this relationship between solution and solid state structures has been proved exactingly in more than ten cases. Examples other than neurotoxins are many protease inhibitors, cytochome $c$ and lysozyme. I return to what I mean by tightlyfolded later. In these well defined interiors B-factors are small. The H/D exchange both in neurotoxins and generally follows the expected patterns in that the $\beta$-sheet regions exchange very slowly, $\alpha$-helical regions generally less slowly and "less stable" bends and exposed fragments most rapidly. A full analysis by NMR of H/D exchange needs great care with the interpretation. As shown by NMR shifts the internal mobility of some residues such as leucines and valines of the neurotoxins is very restricted, flip rates $\leqslant 10^{2}$ per sec, but the flip rates of aromatic rings is usually fast $\geqslant 10^{5}$ per sec so that the core of the protein can breath with a considerable amplitude of movement of up to at least $1 \dot{A}$ and with a high oscillatory rate constant $\geqslant 10^{5}$ per sec. (Notice that it would appear that flips of aromatic groups require less main-chain breathing amplitude than the flips of aliphatic residues). This is far from a true unfolding motion as visualised by LINDERSTRøM-LANG, but it does show the general softness of the interior of even tightly folded proteins. In fact, it would appear that only the very slow solvent $H / D$ exchange rates (rate constants of many days) correspond to such motions as really large-scale unfolding, e.g. the disruption of $\beta$ sheets, where LINDERSTRøM-LANG's views apply most obviously.

Since the structure in the above cases though dynamic in a rotational/vibrational sense is closely represented by 'the' one static structure, all would appear to be well until we ask what was the main purpose of the study of these molecules. Surely this must be to understand the selective binding of toxins to receptors. Here we need to describe the surface structure of the neurotoxins, Figure 1. Now this proves to be a very much more dynamic structure since it is of the very nature of the surfaces of proteins that they contain many residues which give solubility such as lysines, arginines, glutamates and aspar- 


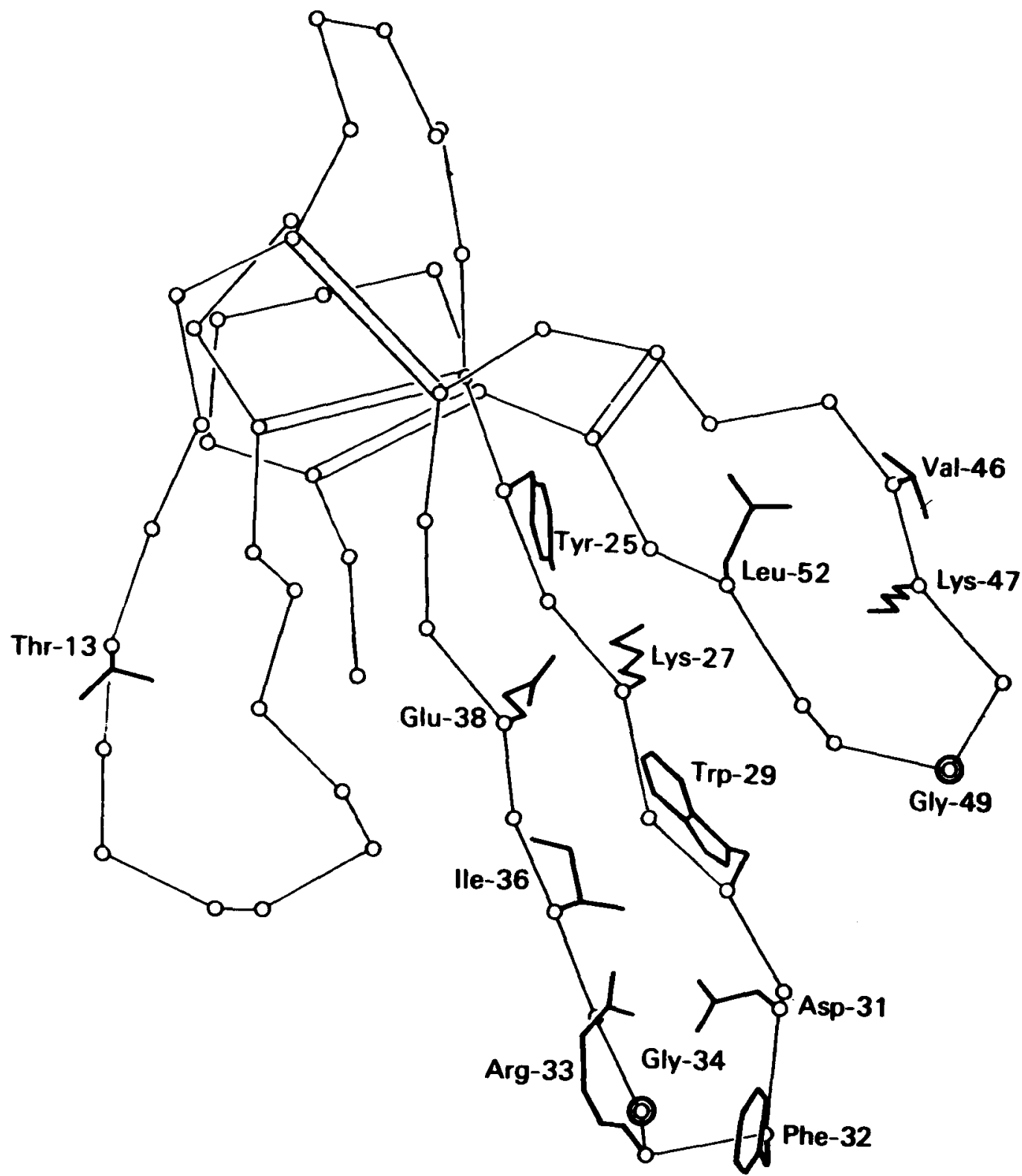

Figure 1. The outline crystal structure of erabutoxin $b$. The side chains of biologically important binding residues ure shown. The $\beta$-sheet, which carries most of these residues, together with the -S-S- bridges make the internal structure relatively rigid. The exterior binding site has both charged and very hydrophobic residues.

tates and which have considerable conformational mobility (39). What can we say about the surface?

Here we face a very real problem. The structures for these side-chains given by X-ray crystallographic examination are often derived from regions of uncertain electron density plus a knowledge of sequence. The interpretation of the electron density map in terms of static structure with either or both thermal motion and thermally controlled disorder added, as described through B-factors, is not enough since 
it can not reveal the probability of visiting many structures of a particular kind occupied $10 \%$ of the time. The surface is trapped in the crystal too. In solution, NMR does not generate a better picture since the structural definition of protein surfaces is not very successful by NMR. There are insufficient data available by the nature of the method. Attempts to describe motion quantitively are then full of pitfalls, but the NMR data leave no doubt that there is very considerable movement of surface residues (18). I have come to the conclusion that the best that can be done in describing a protein surface includes a large number of possible pictures based on X-ray and NMR observations and analysed by energy calculations, but it can only result in a fuzzy picture. This fuzziness is real but limited by packing constraints, and particularly by the strength of the associated backbone structure and so on, and in some places structure may be quite sharply defined. In turn this means that when two (protein) surfaces come together we will find that sometimes there is:

(i) A fitting of two fuzzy surfaces which can remain quite dynamic.

(ii) A tight fitting which allows the side-chains to become well-defined in the final combination although both surfaces are initially quite dynamic.

(iii) A rearrangement of even the backbone so that non-surface residues become part of the interaction.

In the case of neurotoxins I believe that (ii) will be the closest description in the bound state and that we shall find overwhelmingly only one buried structure which now resembles the state of the internal side-chains of a single protein. Why do I say this?

I now return to the problem which we attempted to solve when we studied the neurotoxins - how do they function? At the end of reaction we are looking at the dynamic problem of the ratio of the rate constant for the off-step to the on-step, i.e. the binding constant, but additionally we need to look at the two rate constants separately since it is a feature of biological reactions that their rates are as important as their selective binding. We see this very clearly in the case of a neurotoxin since it must be a fast-acting agent to prevent the escape of the victim. The on-rate must be fast. Additionally, the neurotoxin must escape destruction by the protective proteases of the victim. This last is an irreversible rate process. We then have

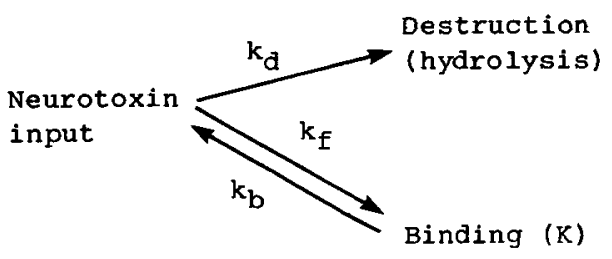

Clearly $k_{f} / k_{b}(f=$ forward, $b=$ back $)$ must give $a$ large $K(\log K \geqslant 10)$ and $k_{d} \leqslant k_{b}$ so that destruction is very slow either directly or via reversible binding. How are the complications of very good binding, which apparently implies very good static structural fitting, and fast on rates, which means considerable mobility, to be managed with little risk of hydrolysis?

We need to re-state the theories of recognition between surfaces. The simplest is the exact matching of the two static objects the die/mould fit, which is sometimes incorrectly called lock and key fitting. Undoubtedly, this perfect matching will give the best binding, but it is not the most valuable to biology since it takes a long time to achieve combination - there could be almost no pathway to the final condition!! The second simplest case is induced fitting when adjustment of two relatively mobile surfaces leads to a very good static final fit, case (ii) above. This is closer to a real lock and key fit since the tumblers in a modern lock move to fit the key's geometric pattern. Here the problem is transferred to getting the key out of the lock. Note that in the case of the neurotoxin this is even not desirable. The final solution is the fitting of two dynamic surfaces in a dynamic union - the hand in glove fit. Now, as we go through these increasingly dynamic modes of structural recognition we increase the dynamics at the expense of the exactness of fit. Thus, we increase $k_{f}$ and $k_{b}$ but $\mathrm{K}$ becomes less selective unless we make more points of contact. We see that biological recognition is a rate process, not a static fitting of structure, so that inevitably the optimal specificity of die/mould has to be sacrificed to action rates. In some processes it is necessary to have both fast on and fast off rates since most 


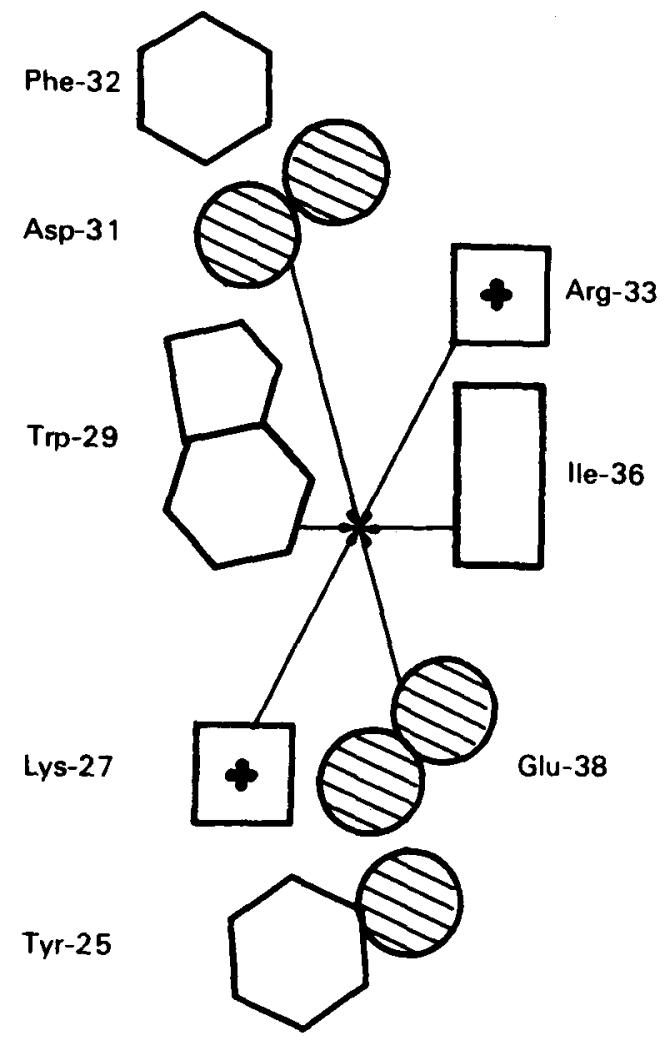

Central loop of erabutoxin b

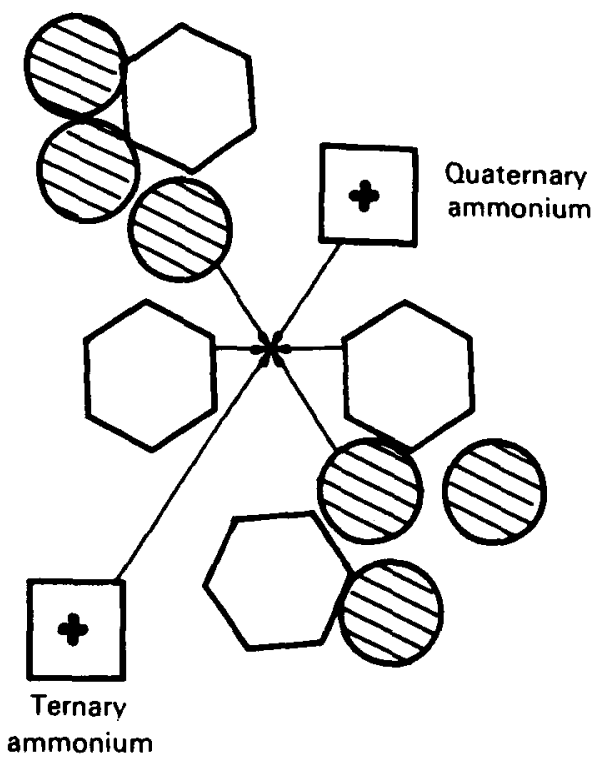

$(+)$-Tubocurarine

Figure 2. A comparison between the structure of erabutoxin convex surface, and the typical structure of a rigid curarine drug. Note the mobility inherent in the charged groups of the protein is absent in the drug.

biological systems must relax quickly after action. Now, if relaxation is to be in the $10^{-3} \mathrm{sec}^{-1}$ range $\mathrm{K}_{\text {binding }}$ cannot exceed $10^{7} \mathrm{M}^{-1}$ since $\mathrm{k}_{\text {on }}$ has a limit of $10^{10} \mathrm{sec}^{-1}$, the diffusion rate. These last extreme conditions need mobile surfaces of both receptor and agonist to which I shall return, case (iii) above.

I come back again to the neurotoxins. We see that perfect very local action, i.e. ignoring any requirement of the toxin to move from the site of injection, demands that $\mathrm{k}_{\mathrm{on}}$ should be fast though it need not approach $10^{10} \sec ^{-1}$ (diffusion limit) and that $k_{\text {off }}$ should be very small. $K$ is then very large. Case (ii) gives a close parallel structural description to this demand: two mobile surfaces freeze after very rapid combination. The neurotoxin needs therefore a relatively well defined structural core to limit conformational states and a dynamic surface. In the real cases the nearly static core is defined by a $\beta$-sheet and several -S-S- bridges, Figure 1, which prevent large excursions of this core so providing (i) a good basis for a final relatively rigid combined (bound) state (ii) little scope for fast attack by proteases or even (iii) little possibility of fast recognition by antibodies (if it is correct that both these recognitions (ii) and (iii) are through some segmental excursion). The surface has a relatively mobile combination of groups. However, now these must be such that additionally they can be readily immobilised in a tight combination with a target receptor. Such an ideal surface structure is achieved in neurotoxins by placing bulky hydrophobic residues such 
as a tryptophan on the surface, see Figures 1 and 2. The bound unit is finally, not initially, jammed into the receptor so that it is very slow to unbind. Now we see not only the purpose of the toxin, but also the strengths and weaknesses of the drugs, curarines, which resemble the neurotoxins and have the following properties, Figure 2.

(i) A core which is not hydrolysable $\left(k_{d} \simeq 0\right)$.

(ii) A rigid structural frame matching the required receptor, $\mathbf{k}_{\text {off }}$ is very slow,

but (iii) little dynamics of the surface so that they are probably slower to bind. This has not been included in man's design of drugs! A second example is morphine which resembles enkephalin only in one of its possible static structures $(21,22)$.

Now when we inspect the actual binding rates for neurotoxins, Table II (19), we find that the on-rates to be about $10^{5} \mathrm{sec}^{-1}$ which is much slower than diffusion rate control, but it is still fast enough to prevent the escape of a prey. The suggestion follows that recognition of the receptor is taking place in steps with a primary fast electrostatic search and matching of relatively poor binding strength and high mobility due to the charged amino acids on the surfaces, Figures 1 and 2 , followed by a more rigid matching in a very selected way due to large hydrophobic residues, but which takes time. A "hand-inglove" initial search is followed by a more "die-in mould" final state. The off-reaction rate is very slow (about one day). This description of initial loose and primarily electrostatic searching-out of a surface followed by tight combination is reminiscent of the description of some reactions of cytochome $c$ on membrane surfaces, culminating in combination with cytochrome oxidase, and of control proteins (repressors) running on DNA until they find specific sets of base sequences $(35,37,39)$.

Given this view of dynamics, we can turn to a variety of biological peptides and ask about their design. The over-riding principle is that "design" (function) is related to rate processes not just static structures. This principle applies to metal ions and small organic molecules as well as to peptides and proteins so that biological choice of organic molecule, peptide or cation is made in terms of selectivity of combinations of
Table II. Dynamics of short and long neurotoxins

\begin{tabular}{|c|c|c|}
\hline \multicolumn{2}{|c|}{$\begin{array}{c}\text { Long } \\
\text { (i.e., } \alpha \text {-cobratoxin) }\end{array}$} & \multirow{2}{*}{$\begin{array}{c}\begin{array}{c}\text { Short } \\
\text { (i.e., erabutoxin b) }\end{array} \\
10^{9}\end{array}$} \\
\hline $\begin{array}{l}\text { Binding } \\
\text { constant }\end{array}$ & $10^{9}$ & \\
\hline Rate on & $10^{4}$ & $10^{5}$ \\
\hline Rate off & $10^{-5}$ & $10^{-4}$ \\
\hline $\begin{array}{l}\beta \text {-sheet } \\
\text { amide-proto } \\
\text { exchange }\end{array}$ & slow & faster (but slow) \\
\hline Tyr-25 flip & fast & slow \\
\hline Phe flip & fast Phe-33 & fast Phe-32 \\
\hline Val flip & $\begin{array}{l}\text { Val-56 } \\
\text { restricted }\end{array}$ & $\begin{array}{l}\text { Val- } 65 \text { and } \\
\text { Leu-52 } \\
\text { restricted }\end{array}$ \\
\hline
\end{tabular}

Temperature-dependent secondary shifts

\begin{tabular}{lll}
\hline $\begin{array}{ll}\text { (i) of side } \\
\text { chains }\end{array}$ & $\begin{array}{l}\text { Trp-29 } \\
\text { Val-23, Val-56 }\end{array}$ & $\begin{array}{l}\text { He-40, Ile-41 } \\
\text { (Trp-29) }\end{array}$ \\
& Leu-43 & \\
(ii) of & Cys-24, Cys-43 & four unassigned \\
$\alpha$-protons & Thr-28, Lys-27 & $\alpha$ CH resonances \\
& Asp-57 & \\
\hline
\end{tabular}

The different lysine, leucine, and isoleucine residues also show different mobilities. In particular, Ile- 40 and Ile-41 (erabutoxin b) on the binding surface are more mobile than Ile- 2 in the core.

rate processes (dynamic structure) to match function, Table II. I turn next to a protein domain which is appropriately Danish - the kringle, Figure 3, but which provides a concave receptor surface and not just a convex surface of an agonist or inhibitor like neurotoxin.

\section{The Kringle Dynamic Structure}

The Kringle domain, Figure 3, occurs in many proteins concerned with blood clotting (prothrombin) and clot removal (plasminogen). The structures of kringle 4 from plasminogen (NMR) $(11,44)$ and of kringle 1 from prothrombin (X-ray diffraction) (25) have been solved to reasonable resolution and show that the kringle fold is largely a common one, Figure 4. This is known from additional NMR data for 


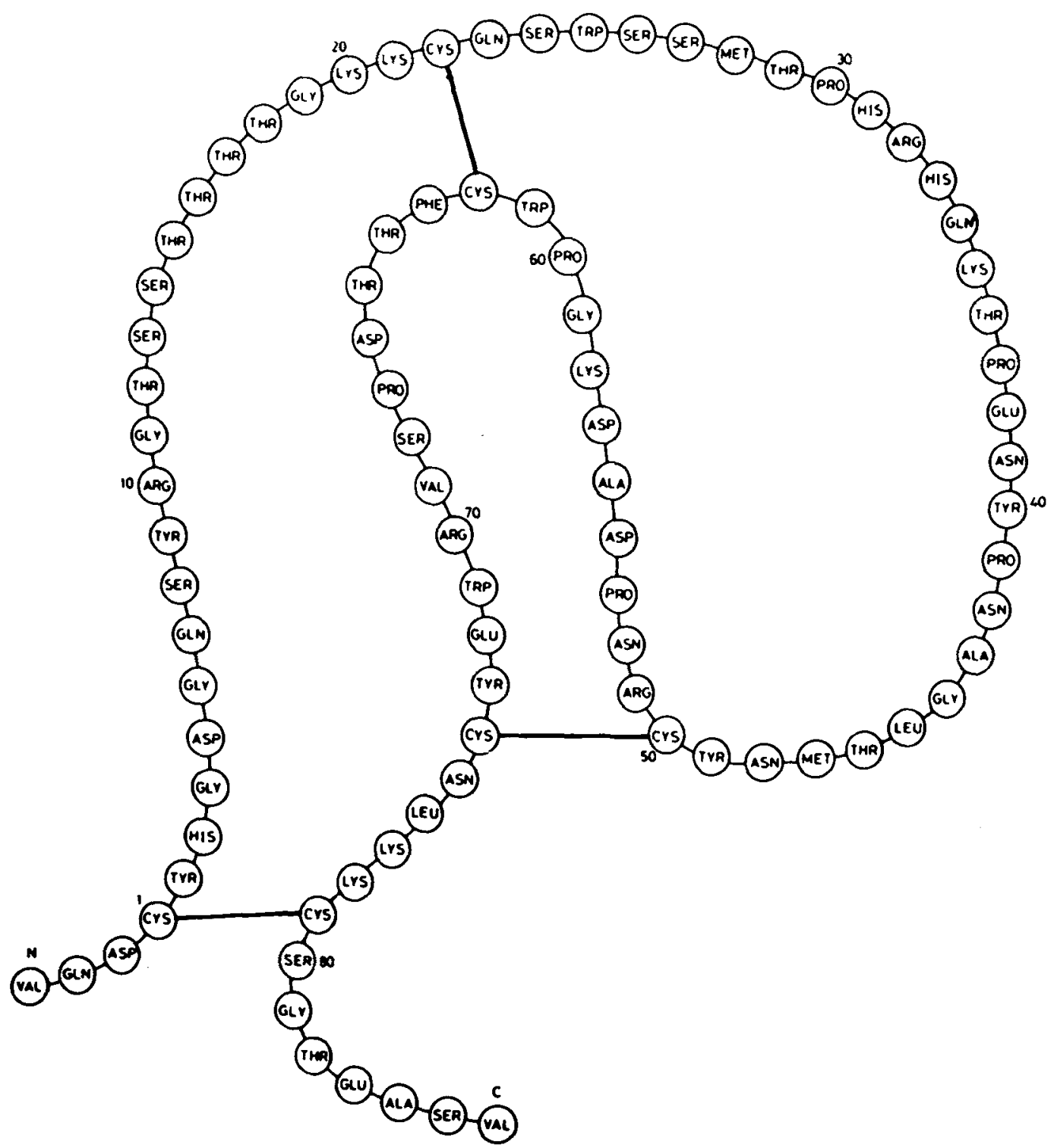

Figure 3. The kringle primary structure with the residues of kringle 4 of plasminogen shown. The name kringle is taken from the Danish cookie.

at least two other kringles. The structure has a small $\beta$-sheet, 3 -S-S- bridges, virtually no helical elements, and several $\beta$-turns. Apart from the general, but not total agreement between the two studies, which were done totally independently, interest here is in the dynamics. It is quite clear that the kringle structure including even the small $\beta$-sheet region is not so very stable. Proto- nation reactions of surface residues (Asp. 54 and 56) affect it. Again, the tails just outside the kringles are highly mobile and easily attacked by proteases. Even the kringle itself is somewhat vulnerable.

Evidence for the mobility comes from various sources. There is good NMR evidence for conformational mobility from the variety of line 


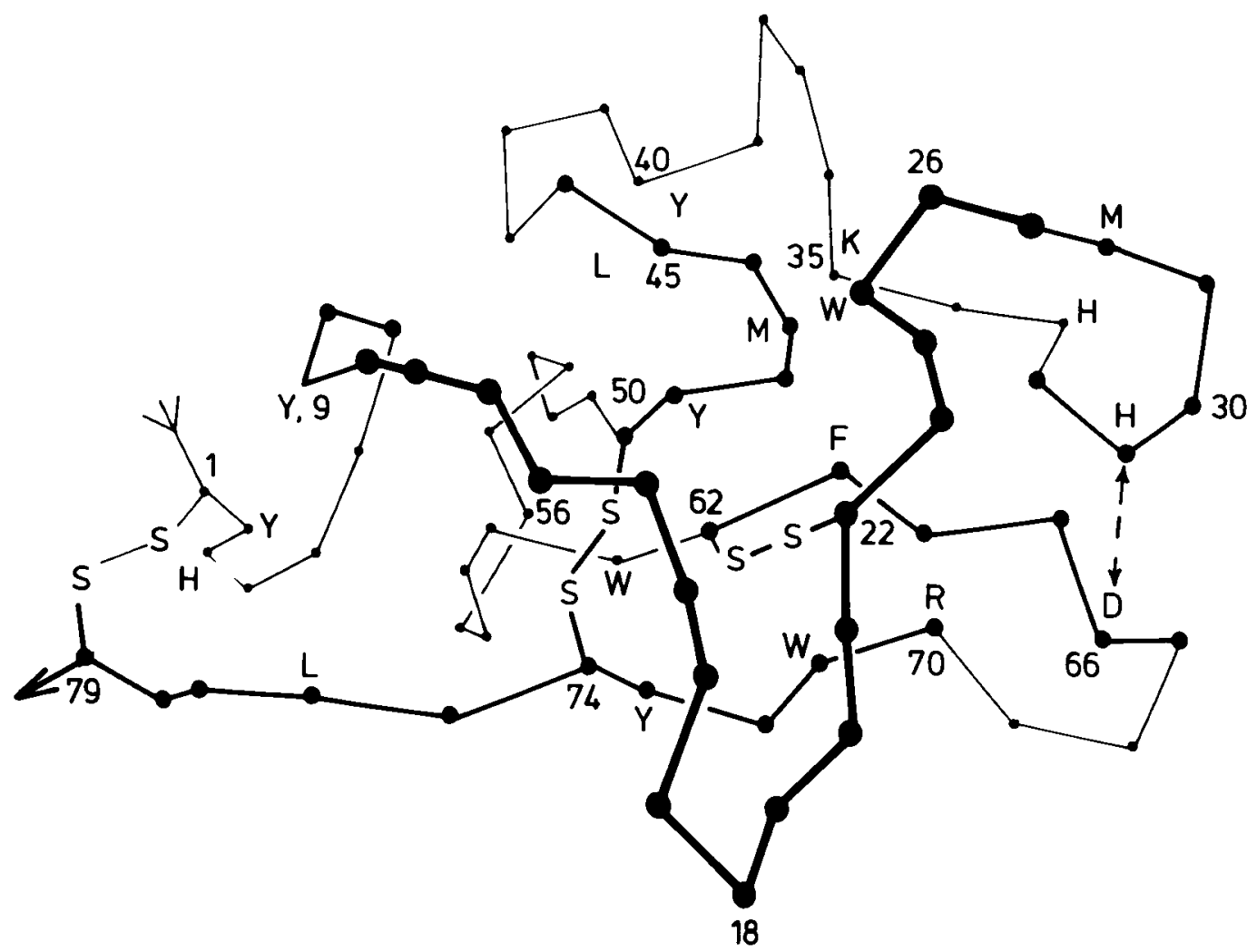

Figure 4. The fold of kringle 1 (prothrombin) from X-ray crystallography and NMR with the sequence of kringle 4 (plasminogen) imposed on it. The super-position is generally legitimate, but there are some structural differences, see reference $(11,15,44)$. There are elements of a somewhat unstable $\beta$-sheet-like structure based on a $\beta$-strand from 61-65. The concave recognition cavity is between Arg 70 to Asp 54 and 56 which makes a kringle a receptor-like molecule.

widths in the spectra, the loss of stability at moderate temperature, the changes in structure on change of $\mathrm{pH}$, and the very small numbers of peptide $\mathrm{NH}$ groups which show relatively slow exchange $(11,44)$. The neurotoxins and protease inhibitors are a much tougher, more static, set of proteins. Functionally, all such features are important and we must look at the same set of rate constants as before.

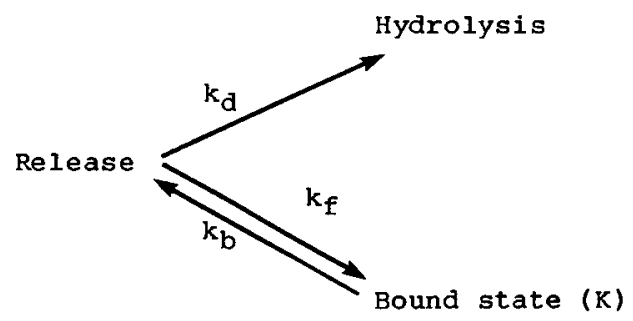

In the case of kringle 4 we know it binds to lysines of partner proteins and lysine-like analogues through a pocket behind the two aspartates 54 and 56 and across to Arg 70. Interestingly, this pocket, now the concave receptor, for this is what a kringle is, has two tryptophans in it, Tryp 71 and Tryp 61 and there is a third one very close behind Tryp 25. Tryp 71 and Phe 63 serve to stabilise the position of the Arg 70 (linked to the $\beta$-sheet too). Only Tryp 61 and 71 move slightly on lysine binding. Of course the lysine is very dynamic before it binds, but it undoubtedly freezes in the kringle pocket. The value of the concave surface of the kringle in restricting mobility is obvious.

The resemblance to the neutrotoxin interaction is close including the use of surface charges 
Table III. Some hormones and transmitter peptides

\begin{tabular}{|c|c|c|}
\hline Peptide & Structure & $\begin{array}{l}\text { Mobility as shown by } \\
\text { NMR studies }\end{array}$ \\
\hline $\begin{array}{l}\text { EGF* } \\
\text { Neurotoxin* } \\
\text { Protease Inhil }\end{array}$ & $\begin{array}{l}\text { Small } \beta \text {-unit } \\
\text {-S-S-bridged }\end{array}$ & Rigid core \\
\hline $\begin{array}{l}\text { Kringle* } \\
\text { Domain }\end{array}$ & $\begin{array}{l}\text { Small } \beta \text {-unit, } \beta \text {-turns } \\
\text {-S-S-bridged }\end{array}$ & Relatively Rigid core \\
\hline Insulin* & $\begin{array}{l}\text { Series of helices } \\
\text {-S-S-bridged }\end{array}$ & Relatively low mobility \\
\hline Glucagon* & $\begin{array}{l}\text { Little structure in } \\
\text { solution }\end{array}$ & Mobile \\
\hline Calcitonin* & Little structure in water & Mobile \\
\hline Mellitin* & $\begin{array}{l}\text { Little structure in water } \\
\text { simple helix in membrane }\end{array}$ & Mobile \\
\hline Enkephalin* & Little structure in water & Mobile \\
\hline $\begin{array}{l}\text { Neurotensin } \\
\text { Bradykinin }\end{array}$ & $\begin{array}{l}\text { (Single } \beta \text {-turn in organic } \\
\text { solvents) }\end{array}$ & Mobile \\
\hline
\end{tabular}

and tryptophans. However, it would appear that in all respects the interaction here does not have the same strength nor is it so tightly frozen (rate process) in the combination. The reason could be the desirability for relaxation of the reaction and removal of the activity by hydrolysis in a matter of minutes. A blood clot must be partly ramoved on the internal side of a protective scar. We shall see that as peptides themselves and in their combinations become more mobile - often with a drop of binding constant from $10^{12} \mathrm{M}^{-1}$ toward $10^{8} \mathrm{M}^{-1}$ - so the function usually changes to allow not only more rapid on reactions but also more rapid relaxation and destruction. On the path to destruction of the blood plasma proteins is the easy hydrolysis of links between several kringle domains, and it is known from NMR that these links are often extremely mobile. We shall see again and again how alternation of mobile and more rigid structures allows domains to be used and then destroyed in signalling outside cells.

\section{Hormonal and Transmitter Peptides (21)}

Inhibitor peptides such as protease inhibitors and neurotoxins are based on the principle that they should not be open to easy degradation. Hormones can be similar or can be very different depending upon whether the hormone is to have relatively constant effect over long periods of time only altered at particular periods or whether it is to be used only in pulses, Table III. (Often this may mean that the difference is found in the distance a hormone travels to its target since a short distance gives a fast effective on-rate). With this background in mind it is instructive to look at hormone structures. Table III gives some examples from which we see that there is a wide variety of structural types, but as 
yet there are few examples which include a $\beta$-sheet in the structure. The contrast with the inhibitor peptides is striking. Starting with the larger peptides the most structured hormone after the EGF growth hormone is insulin (8), but by several methods of study this peptide is conformationally mobile, i.e. relative to neurotoxins, e.g. H/D exchange, crystallographic forms, NMR analysis of ring-flipping, and so on. It is probable that there is considerable helix/helix motion, i.e. segmental motion. Glucagon is even more mobile and it is doubtful if it has a well-defined fold in aqueous solution although there is a crystal structure.

We can again consider the equation:

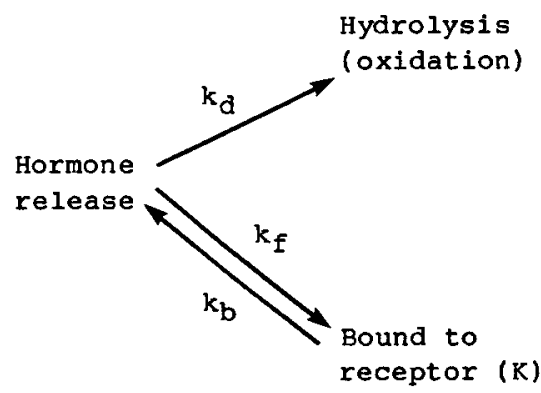

Clearly, $k_{d}$ is now large and while $k_{f}$ is likely to be close to the diffusion limit, $\mathrm{k}_{\mathrm{b}}$ must also be large enough to allow relaxation. How is all this managed?

Here we must begin with the release step which is not a simple injection, but is itself an hydrolysis step. The smaller hormonal peptides such as ACTH exist in a storage form within a long precursor peptide from which they are released by proteolysis. The precursor is only saved from hydrolysis as is the hormone itself by the vesicular storage in cells away from the circulation proteases. The released peptides in this class which we and others have studied by NMR methods show very little evidence of a fold in water, but it is frequently the case that they do fold in a non-aqueous medium to give in the case of the smaller peptides simple structures such as a single helix, mellitin, or a $\beta$-bend, enkephelin. These peptides are only protected from destruction in their bound forms. They then have a very fast $k_{o n}$, a large $k_{\text {off }}$ and $k_{d}$. In fact, the situation is not very different from that of the structures of the antigenic peptides, see below.
As a final example of a hormonal peptide we return to insulin which represents a curiously intermediate case. Undoubtedly, its surface is highly mobile. Moreover, it is a helical protein, not a $\beta$-sheet, so that its internal mobility, as shown by somewhat different helix/helix packings in different crystal forms, is also comparatively large (8). However, it is strongly -S-Sbridged. Can we presume that the requirement is for a relatively long persistence of this hormone, long life, which amounts to protection from hydrolysis, but that the requirements for adjustments on binding to receptors have been suitably built into a compromise structure? In other words, is insulin some way along the line from inhibitors $(45,46)$ and toxins (19) to calmodulins (see below). Are the EGF peptide and the kringle just one step nearer the toxins (Table III)? The excursions of the helices of insulin may make it just somewhat vulnerable to hydrolysis by proteases. Once again we should remember the early studies and thoughts of LINDERSTRøM-LANG. (Note in passing that insulin is bound by both calcium and zinc which is reminiscent of the S-100 calmodulin-like proteins. We return to the involvement of these two special "mobile" cations later in this article).

\section{Antigenic Peptides}

Antigenic peptides made by man are frequently based today on repeat sequential motifs found in antigenic regions of proteins, Table IV. We note immediately that this class of antigen sequence of a protein is not the only type possible since antigenic regions can encompass amino-acid residues not connected in the sequence, but spatially related by a fold. This second class of antigenic site is not of great concern here. The sequential peptide antigen is usually short, not more than 10 residues and shows only some evidence of a fold in water. The suggestion has been made that in the parent protein these peptide stretches may well be more strongly folded and partially hidden by the total fold. However, even in the protein they are sufficiently mobile to be exposed for at least some of the time $(9,34,42)$. In essence in this view it is not constant exposure which reveals the antigenic group, but surface zones of 
Table IV. Sequences of some antigenic peptides

Protein

Hemagglutinin, $\mathrm{HA}_{1}$

Influenza Virus Hemagglutin

Human chorionic gonadotropin

Human IgG

Cholera Toxin

Malaria Antigens
Antigenic Region

V.K.R.G.P.D.S.G.V.

Y.P.Y.D.V.P.D.Y.A.

D.D.P.R.F.O.D.S.

T.K.P.R.E.Q.Q.Y.D.S.T.Y.R.

V.E.V.P.G.S.Q.H.I.D.S.Q.K.

(a) E.E.N.V.E.H.D.A.

(b) N.A.N.P.N.A.N.P.N.A.N.P.

Note: The antigenic sequences often contain a surface, loose, $\beta$-turn and it maybe that it is a partial rearrangement of these turns from the native rather mobile conformation of the parent protein which allows antigenicity to be expressed. The presence of several hydrophilic residues will assist this mobility. Data in the table are from "Synthetic Peptides as Antigens", Ciba Foundation Symposium, 119, (Eds. R. Porter and J. Whelan) John Wiley and Sons, Chichester, 1986.

proteins which can readily be revealed, i.e. mobile short segments of a sequence. Naturally, the segments are on the surface and therefore have a high degree of exposure or accessibility too. It is not surprising that these very segments are often rather open to proteolysis and show quite rapid H/D exchange. Importantly for the idea that antigenicity is associated with mobility of segments it should be that some of the more buried parts of the segment sequence are an essential part of the antigenic strength since otherwise the mobility is less important than the exposure, Table IV. The buried residues are likely to be hydrophobic, for obvious reasons.

Mobility always has some part to play in the docking of receptor and hormone or antigen and antibody as stressed above. Apart from the fitting requirements there is the requirement in an antigen for the response to be relatively fast. However, the off-reaction should be slow and in this sense it can be likened to an inhibitor peptide. To achieve this multitude of functions I expect at least one strongly hydrophobic amino-acid to be included in the sequence. It is likely to be the buried amino-acid. The antigenic peptide is to some extent then intermediate in properties between the fast on/off relatively weak binding of a hormone and the fast on/very slow off of the inhibitors. As I stress throughout this article, speed and specificity are not compatable partners. This turns us for a moment to small organic-molecule transmitters and hormones, which are not peptides.

\section{Small Molecule Hormones and Transmitters}

There is of course a parallel between the variety of stability of peptide hormones and the variety of stabilities of other types of transmitters and hormones, Table V. An extreme example of very fast $k_{\text {on }}$, large $K$, fast $k_{\text {off }}$ and fast destruction is acetylcholine where the choline esterase is

Table V. Characteristics of small molecule hormones and transmitters

\begin{tabular}{ll}
\hline Small Molecule & Properties \\
\hline Acetyl Choline & $\begin{array}{l}\text { Mobile, readily hydrolysed, } \\
\text { short life-time }\end{array}$ \\
$\begin{array}{l}\text { Several } \\
\text { Amino-acids }\end{array}$ & $\begin{array}{l}\text { Mobile, removed rapidly } \\
\text { by uptake }\end{array}$ \\
Cyclic Nucleotides & $\begin{array}{l}\text { Not very mobile, readily } \\
\text { hydrolysed, short life-time }\end{array}$ \\
Amines: 5-hydroxy & $\begin{array}{l}\text { Not mobile, readily oxidised, } \\
\text { relatively short life-time }\end{array}$ \\
tryptophan, & \\
Strenaline & Rigid, slow destruction, \\
Progesterone, & sustained effect \\
Oestradiol & $\begin{array}{l}\text { Relatively rigid, protected from } \\
\text { oxidation, sustained effect }\end{array}$ \\
Thyroxines &
\end{tabular}

N.B. Oxidation as a mode of removal is not so dependent on mobility as hydrolysis since electron transfer itself has a low binding and mobility requirement. 
closely associated with the synapse. Diffusion away from either the sites of production and destruction is very restricted by vesicle release and local enzyme destruction. Note that this is a freely, internally mobile ester, not an amide (a peptide) and that peptides generally have a longer life than esters. Erabutoxin $b$ which is relatively rigid, see above, binds to the acetylcholine receptor, but much more slowly than acetyl choline. A longer life-time is likely too for small molecules only open to oxidative attack, for example adrenaline and 5-hydroxytryptamin (note the increased rigidity due to the larger framework), but even they are often rapidly destroyed by closely located amine oxidases. A much longer lived species is the group of sterol hormones which are slow acting and maintain general steady state control. Note the rigidity of the latter and the flexibility of the former molecules, Table V, and that the frame is now inert to both hydrolysis and oxidation. In fact, we can see a parallel between the uses of rigidity and mobility in peptides and in organic molecules in biology. The parallel extends to the use of simple inorganic cations, which also fall into more rigid and more mobile classes in their complex ions, see below. All three groups of compounds serve as transmitters of information.

\section{Mobile, Swinging-Arm, Peptides}

There is now considerable evidence for differential mobility of peptide segment domains within proteins generally (e.g. antigenic regions), but there is also evidence for larger motions of domains especially within very large protein organisations. The domains are not freely diffusing bodies relative to one another, but they have the same on/off rate processes as two separate combining proteins, e.g. the neurotoxins and a receptor, and their rates of reaction are also of functionally tuned value. We illustrated this theme with the kringle domains. There is one further interesting possibility. Especially the C- or N-terminal stretches of amino acids can be such as to provide a mobile arm. Several examples are now known, but their sequences give further cause for thought. It is the inclusion of proline in the "mobile" arm peptides of muscle and in swinging arms of multienzyme complexes which is so thought-provoking, Table VI. Proline acts as a constraint on mobility yet it is in these very mobile segments. The sequence Ala-Pro-Ala common in these peptides segments means that the peptide arm must be jointed rather than totally floppy, and such an arm then has a limited space which it can visit by conformational mobility. Its use in the transfer of energy (muscle) or of a group (certain acetyl transferases) is perhaps that the arm does not do a fully random search as it carries the substrate or information from point to point, but it is more or less on a trajectory from source to sink. Note that the on/off reactions of the arms must be fast so that binding constants themselves may well be modest although on rates are much helped by the absence of diffusion. Once again there are parallel organic molecules with arm-like mobility, e.g. pantethenic acid, lipoic acid, attached chromophores, plastoquinones and so on which may be required for selected motion and transfer of chemical groups.

Table VI. Some arm-like mobile peptides (protein fragments)

\begin{tabular}{|c|c|c|}
\hline Peptide & Sequence & Ref. \\
\hline $\begin{array}{l}\text { N-terminus of the LC. } 1 \\
\text { Myosin alkali light chain }\end{array}$ & $\begin{array}{l}\mathrm{Me}_{3} \text { A.P.K.K.N.V.K.K.P.A.A.A. } \\
\left(\text { A.P.) }{ }_{7} . \text { A.K.P.K.E.E.K.I.L. }\right.\end{array}$ & (1) \\
\hline Ton - peptide & $\begin{array}{l}(\text { E.P. })_{4} \text {.I.P.E.P.P. K.E.A.P. } \\
\text { V.V.I.G.(K.P. })_{6}\end{array}$ & (12) \\
\hline $\begin{array}{l}\text { Terminus of pyruvate } \\
\text { dehydrogenase complex }\end{array}$ & $\begin{array}{l}\text { A.A.P.A.A.A.P.A.K.Q.E.A.A.A.(P.A. })_{2} \text {.A.K. } \\
\text { A.E.A.P.A.A.A.P.A.A.K.A. }\end{array}$ & (26) \\
\hline
\end{tabular}

N.B. Proline residues are italicized, see text. 


\section{Peptides and Biological Space}

So far we have described peptides which are in very different parts of biological space although they are in aqueous media. The rigid neurotoxins and protease inhibitors circulate in the extracellular space and are always open to protease attack. The hormonal peptides, usually mobile, are stored in vesicles and do not risk attack until released when in fact they must be quickly attacked. (I shall come back to the fact that their proteases are frequently zinc-dependent). We turn later to another class of small proteins or peptides also in aqueous solution but now protected from attack by being in the cytoplasm but before doing so we should look at membranebound peptides since they too escape the attention of proteases.

\section{Membrane Peptides}

Several membrane peptides have been studied by NMR in lipid or hydrophobic solvent media. Examples are given in Table VII. These peptides are usually simple helices with perhaps a single bend in them, Figure 5. Knowledge of
Table VII. Membrane peptides

\begin{tabular}{|c|c|}
\hline Peptide & Comment \\
\hline Gramicidin A & Short helical segments in dimers \\
\hline Alamethicin & $\begin{array}{l}\text { Helical rods ( } n \text {-mers) transverse } \\
\text { membrane }\end{array}$ \\
\hline $\begin{array}{l}\text { Peptide C }\left(\mathrm{F}_{\mathrm{o}}\right) \\
\text { (ATP-synthase) }\end{array}$ & $\begin{array}{l}\text { Double helical rods ( } n \text {-mers) trans- } \\
\text { verse membrane twice }\end{array}$ \\
\hline Mellitin & $\begin{array}{l}\text { Helical rod (parallel with mem- } \\
\text { brane) }\end{array}$ \\
\hline Haemolysins & Helical rod (orientation not known) \\
\hline
\end{tabular}

Note: Alamethicin or gramicidin are sustained poisons just as is a neurotoxin, but they affect a very different process, ion entry into cells, and escape destruction through proteases by lying in membranes. They can be mobile, but have long-life. I am grateful to Prof. $\mathrm{K}$. WüTHRICH and Dr. I.D. CAMPBELL for published and unpublished information about some of these peptides.

their structures and functions suggests that they are often polymerised and in these polymerised states the helix/helix movements are relatively

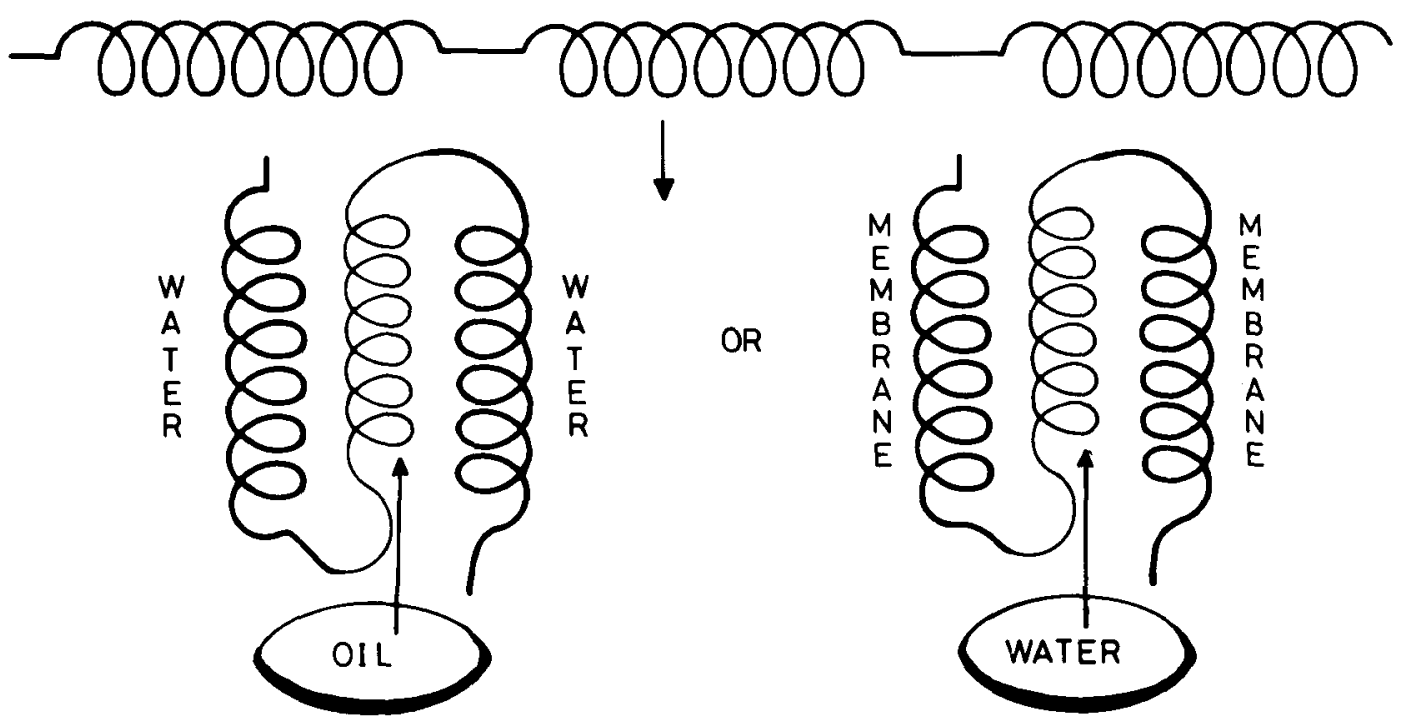

Figure 5. The folding of two helical peptides. The first is a water soluble peptide of the calmodulin EF-hand class, the second is a membrane soluble peptide of the bacteriorhodopsin class. The first is stabilised by hydrophobic surfaces which are the necessary regions for helix/helix motions and become binding areas for drugs. The second is stabilised by interior $\mathrm{H}$-bonds and perhaps water and they generate ion channels for gated, pumping and ion gradient driven reactions. 
easy. The relative mobility of the helices is probably associated with the function of many such peptides as ion channels $(13,32,41,43)$. In other words the interior fold of the peptides are designed to be associated with a dynamic process. As the ion passes along the channel there must be some relaxation of side chains. In the case of energised transport ion binding in the channel may also be associated with a conformation change of several helices where the helices can slip and rotate relative to one another. This could be very useful in controlled pumping of ions. The reversible link to energy in the form of ATP hydrolysis or synthesis may well then be through the coupling of the helix motions to the kinase like ATP-ase or ATP-synthase enzymes (43). We shall note later that the helix/helix motions are of the essence of the kinases themselves in one of their domains. Many of these membrane peptides contain a single proline which gives a kink to the helix. The purpose is not known.

In membranes there are also organised systems for the transfer of light energy, light harvesting domains, and for electron transfer. Neither of these transfer processes require anything, but the minimum of dynamic processes since the transfer step is exceedingly rapid, $10^{12} \mathrm{sec}^{-1}$. The Franck-Condon barrier is overcome by local vibrational terms, see p. 2 . However, biology has to couple the energy of light capture and electron transfer to chemistry, ATP-formation, and here it is found to be necessary to generate initially ionic coupling. Most commonly the movement involved in coupling is of protons in the membrane. The coupling devices for the gated movement of protons connected to either light absorption or electron transfer would appear to rest in the relative motions of tightly packed helices in or very closely associated with membranes. Examples are given in Table VIII.

\section{Summary of Extracellular Systems}

Before turning to the value of dynamic structure in intracellular peptides and noting that we shall need to refer to the use of metal ions before doing so it is useful to have a short summary. We have observed that whether we consider small molecules, small proteins or peptides or domains within large organisations there is a great
Table VIII. Bio-energetic coupling fragments

\begin{tabular}{ll}
\hline Fragment (helical) & Function \\
\hline Cytochromes $b$ & $\begin{array}{l}\text { Coupling of electron to pro- } \\
\text { ton movement in particle III } \\
\text { (Mitochondria and chloro- } \\
\text { plasts) }\end{array}$ \\
$\begin{array}{ll}\text { Coenzyme Q binding } \\
\text { protein }\end{array}$ & $\begin{array}{l}\text { Coenzyme Q/Chlorophyll re- } \\
\text { action centre of photobacte- } \\
\text { ria site) }\end{array}$ \\
Bacteriorhodopsin & $\begin{array}{l}\text { Cis/trans conformation } \\
\text { change of chromophore }\end{array}$ \\
Chlorophyll-binding & $\begin{array}{l}\text { Energy transfer, then } \mathrm{H}^{+} \text {gra- } \\
\text { dient production }\end{array}$ \\
\hline
\end{tabular}

variety of degrees of mobility within structure. The variety extends from the most rigid protease inhibitors to almost random-coil proteins which are totally vulnerable to protease action. Intermediate cases represent chemicals of controlled lifetime which through their limited mobility and consequently controlled vulnerability to proteases can be chopped at controlled rates into fragments which themselves have controlled mobility related to function - speed of action and speed of destruction. While the major focus has been on the back-bone motions the actual binding steps in recognition between more rigid bodies depend upon the mobility of side-chains. The latter are frequently the most important mobile elements of enzymes, but we have seen that even here groove-closing (lysosyme), hinge bending (kinases) or arm-swinging (acetyl transferase) have their particular value in activation, in limiting reaction space, or in controlling diffusion. We shall return to the effect of the composition, hydrophilic or hydrophobic, upon the dynamics of these surfaces and their reactions later. My stress throughout is deliberately upon the different value, the specificity, of the different selected dynamics allowed in a peptide.

Instead of giving further examples of peptide action I wish next to turn to a parallel set of activities to those of peptides - the actions of some metal ions, especially zinc and calcium which I shall look at for their ability to act as transmitters and hormones. Finally, I shall bring together the description of cellular control by the 
combination of peptide, small molecule, and metal-ion activities - allodynamics. In all activities there is a degree of static structural complementarity on binding, but action is supplemented by a degree of matching of dynamics.

\section{Metal Ions as Hormones or Transmitters (41)}

The two metal ions on which I concentrate in this article are zinc and calcium. One other cation has similar binding/mobility features the proton (36). It is a feature of an organic hormone or a transmitter such as a peptide that it must follow the pattern of turnover:

Syntheses $\rightarrow$ Release $\rightarrow$ Effect $\rightarrow$ Removal (Degradation)

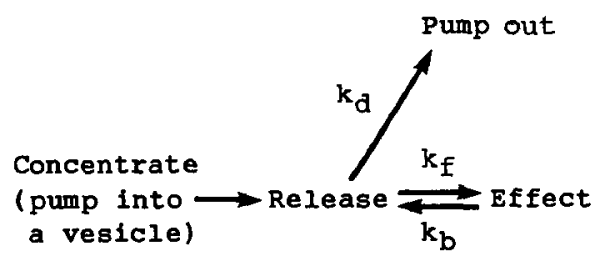

The parallel route for an indestructible metal ion is:

Energy is utilised in concentrating and not in a synthesis, but there remains the common features of rapid diffusion, controlled (fast) on reactions, slow release and controlled removal. Two comparisons of fast and slow acting metal ions are those between calcium (fast) and magnesium (slow) and between zinc (fast) and nickel (slow), see Table IX, for the rate of combination of each metal ion is based on rate of water removal from the ions. It is to the chemistry and biochemistry of calcium and zinc to which we turn next.

Table IX. Fast and slow acting metal ions (41)

\begin{tabular}{lll}
$\begin{array}{l}\text { Metal } \\
\text { Ion }\end{array}$ & $\begin{array}{l}\text { Rate of water } \\
\text { exchange (secs) }\end{array}$ & Typical activity \\
\hline $\mathrm{Ca}^{2+}$ & $10^{-9}$ to $10^{-10}$ & Universal trigger \\
$\mathrm{Zn}^{2+}$ & $10^{-9}$ & Special trigger (hormone)? \\
$\mathrm{Mg}^{2+}$ & $10^{-6}$ & Phosphate transfer \\
$\mathrm{Ni}^{2+}$ & $10^{-4}$ & At enzyme sites only \\
\hline
\end{tabular}

\section{Parallels between Zinc and Calcium Chemistry}

At first sight zinc and calcium are quite different elements $(40,41)$. The most striking difference is the electron affinity of the cations making zinc a good Lewis acid capable of binding partly covalently to nitrogen and sulphur donors, whereas calcium is a poor Lewis acid and binds only to oxygen donors through electrostatic forces. This difference still allows, however, that they could behave functionally in a similar way, but using different donors. Put simply the hypothesis is that while calcium has its role in modulating biological activity through fast binding to oxygen donor centres such as carboxylate and neutral oxygen (carbonyls and alcohols), zinc has an identical role, but it modulates activity by fast binding to thiolate(S) and imidazole( $\mathrm{N}$ ) centres. Using the two metal ions rather than one gives biological systems a wider range of switch mechanisms than using one alone. The similarity between the two cations arises not in the nature of the groups bound, but in stereochemical flexibility and in the rates of binding and dissociation. Both zinc and calcium show a wide variety of coordination numbers and geometries - they are not polarisable cations nor are they very small. This lack of geometric constraint is related to the fact that both can exchange water for another group at rates close to the diffusion limit and their offrates from ligands are then related to their binding constants. Cations of equal or better electrostatic binding strength than calcium, and which are available, are limited in biology to $\mathrm{Mg}^{2+}$ ions which have well-defined geometry and slow on/off rates. Cations of equal Lewis acid strength to zinc, e.g. $\mathrm{Ni}^{2+}$, also have well defined geometry in complexes and react slowly. For zinc and calcium (and for very few other cations) considerable binding strength goes with fast response, but in different chemical environments. We may then compare random-coil and multi-helical peptides with zinc and calcium (and acetyl choline) and $\beta$-sheet peptides with magnesium and nickel (and sterols). In fact, it is part of the message of this article that zinc and calcium are like hormones and transmitters in that they are deeply involved in a large number of control mechanisms which require rapid 
reactions (and relaxations) from fertilisation, through cell division, to messenger response, and even up to such devices as blood-clotting control. However, the organic (peptide) and inorganic components of control are not just parallel, but they are interwoven and both depend on dynamics. It so happens that the fastest reactions are associated with calcium since it is the weaker Lewis acid and binds electrostatically.

\section{Signalling : Calcium (and Zinc) (38)}

The capability of both these elements to act as fast activators of chemical systems through fast on and off reactions together with their considerable binding strengths (which allows them to drive conformation changes) is an immediate indication of their potential as signalling ions in biology. If they are to be used in this way then it should also be observed that they must have large concentration gradients within biological systems. These gradients and the apparatus for their use, pumps and channels, have been found for calcium. For zinc there are data showing that large concentration gradients exist, but there is no knowledge of a link to metabolism of pumps or to a set of channels. The pumps must surely exist to explain the gradients. Channels may not be necessary since internal excitation of a cellular system can be managed by the discharge of zinc (calcium) from vesicles. Zinc (calcium) is known to be so stored. A final requirement for a signal-ion is a receptor. The receptors for calcium are well-known - the calmodulins - and in other cases intracellular proteins are injected from low into high extracellular calcium media so that high calcium is itself the receptor for such proteins as digestive pro-enzymes. One or two zinc receptors are appearing, the most noticeable of which are the transcriptase factor $\mathrm{TF}$ IIIA, or the zinc-fingers, and S-100. However, chromosomal structure also contains a metalloprotein, sometimes thought to be a copper protein, which is at the centre of condensed nucleosome material. In my opinion it will turn out to be a zinc protein and I believe that we shall find many more.

Now in order to act as a signal we must look at the problem in terms of the equation:

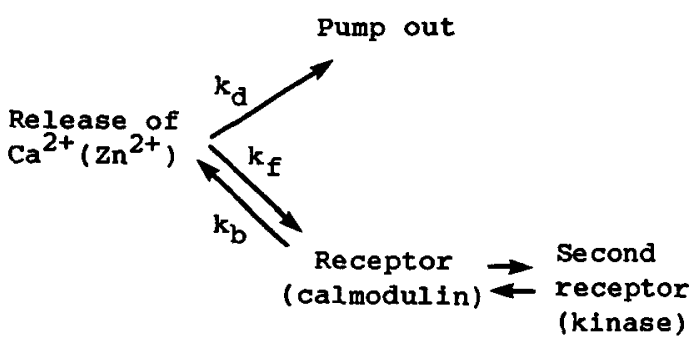

The examination of calmodulin will lead us to a more defined view of the dynamic principles of metal ion and of peptide (protein) receptor motions in the cytoplasm. Notice how the role of the peptide is seen here as the receptor (as in the case of the kringle), whereas the role of neurotoxin was likened to that of an antagonist or agonist. Since we are now dealing with fast response and relaxation mobility will be quite different from in the inhibitors, neurotoxins.

\section{Calmodulins}

The control which resides between calcium injection and action rests upon at least three different calmodulin like proteins all of which we have described by NMR methods. They are calmodulins (troponin $\mathrm{C}$ ), intestinal binding proteins, and parvalbumins (7). To these we should add the S-100 proteins which may well be calcium and zinc modulated. (We must always be aware of proton activity changes too, see $\mathrm{C}$-peptide above, and maybe the $\mathrm{F}_{0}$ of ATP-ase should be called a proton-modulin). All these proteins are helical bundles, Figure 5. In the proteins there is a concave calcium-receptor site, Figure 6 , and calcium binding to it causes helix/helix rotation and lateral motion on binding at the paired EF-hands which are linked in a very small two-strand $\beta$-sheet, Figure 6 . The dynamics of water exchange from the calcium ion give an on-calcium rate of about $10^{9} \mathrm{sec}^{-1}$, and the binding constant then gives an off-rate of $10^{3} \mathrm{sec}^{-1}$ (which is the protein relaxation rate), and a binding constant of $10^{6} \mathrm{M}^{-1}$ for calcium to calmodulin (weak) hands. This is about as good as biology can do in the way of a fast mechanical response. The binding constant cannot be bigger at this response speed and as a consequence selectivity is sacrificed such that selectivity against magnesium is only just adequate. 


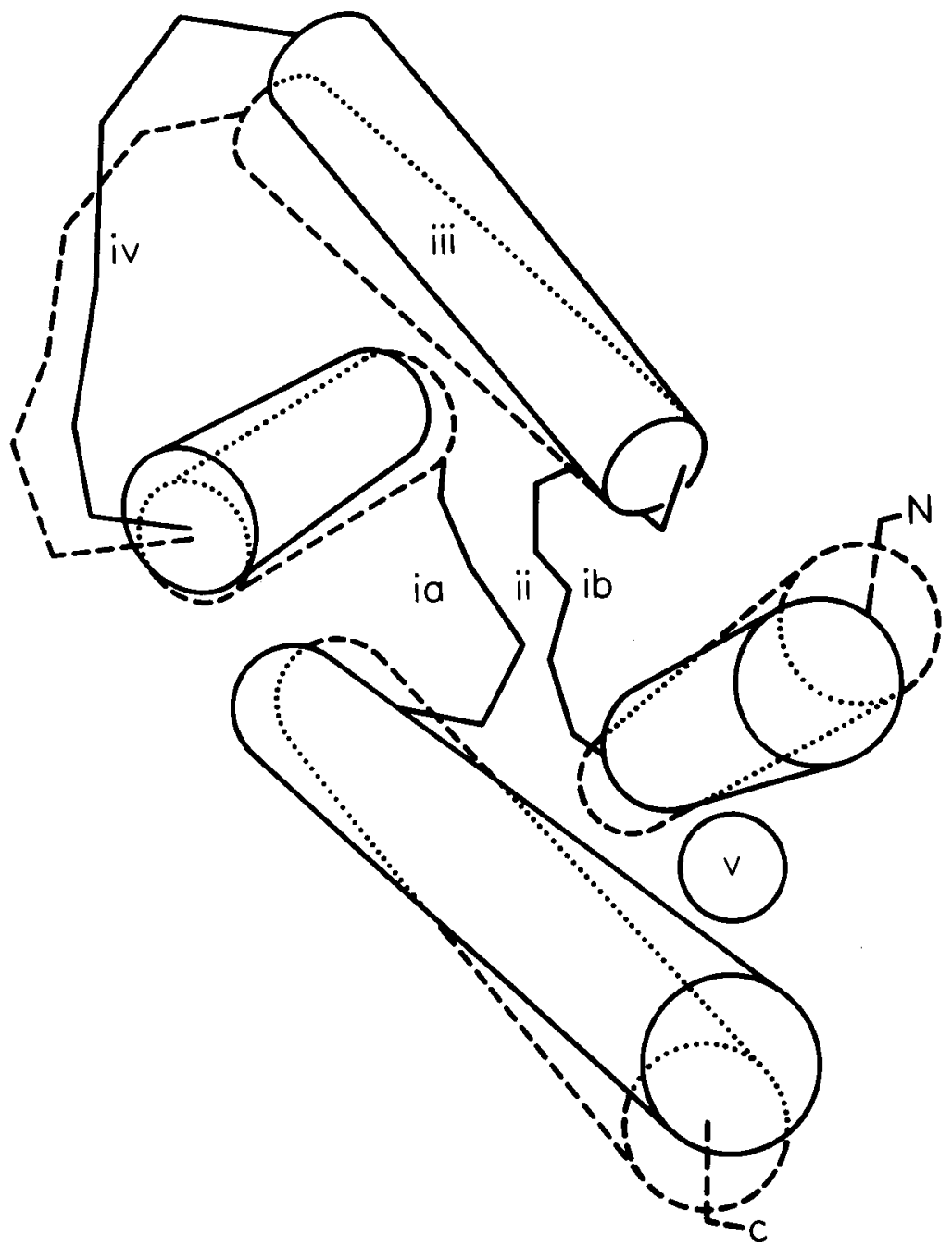

Figure 6. A schematic diagram deduced from NMR data and fully in accord with X-ray structure determinations of the way in which calmodulin acts as a transmitter of the calcium signal. Calcium binds at the small $\beta$-sheet (ii), i.e. the two concave sites ia and ib. The small twist imparted to the sheet by this binding is relayed by the four helices, e.g. iii, to the distant connecting strand iv. The change in helix/helix pattern is shown. The site $\mathrm{V}$ is where drugs bind to the partly hydrophobic surface. The fulcrum of three aromatic residues lies just above the $\beta$-sheet.

The use of three conserved fast-flipping aromatic residues to provide mobility at the fulcrum of the proteins Figure $6(7)$ is in keeping with the fact that such residues become mobile more readily than do aliphatic residues such as valines and leucines in the interior of proteins. Minimal eccentric motion occurs at such a fulcrum.
Using the same EF hands but with a bigger binding constants for $\mathrm{Ca}^{2+}$ (and $\mathrm{Mg}^{2+}$ ) as in parvalbumin gives a slower off-rate for calcium, but it also gives a slower on-rate for calcium since these hands bind magnesium at cytoplasmic concentrations. The selectivity has been deliberately thrown away in order to control the on-rate. The calcium on-rate is controlled by the 
magnesium off-rate, $10^{3} \mathrm{sec}^{-1}$ (the binding constant for $\mathrm{Mg}^{2+}$ is $10^{3} \mathrm{M}^{-1}$ since the on-rate for $\mathrm{Mg}^{2+}$ is only $10^{6} \mathrm{sec}^{-1}$ ). Thus parvalbumin binds calcium better than does calmodulin, but it receives calcium so much more slowly that calcium binds first to calmodulin. We then have an extension to our flow chart based on rate not binding control:

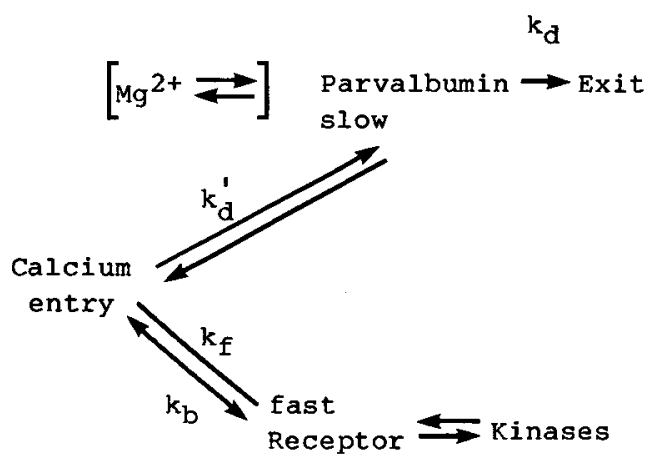

Parvalbumin then becomes part of the relaxation. Notice that all of the peptides freely adjust helices by rotational/lateral motion at rates of $10^{3} \mathrm{sec}^{-1}$. These are outstanding examples of rate control not binding constant control of action with a poor selectivity. The dynamics of metal ions and proteins in concert provide the "allodynamic" response. In all such cases the protein has a large variety of states open to it and the occupancy of the states as reflected in such quantities as calcium kinetics (on/off rates) and binding data can be modulated by other metal ions $\left(\mathrm{H}^{+}, \mathrm{Mg}^{2+}, \mathrm{Cd}^{2+}\right)$, by drugs (trifluoro-piperazine), or binding proteins, e.g. in intracellular calcium proteases, which effect the average conformation of the whole proteins. Further and different examples concern protein kinase $\mathrm{C}$ which I shall describe elsewhere, where the receptor/kinase interaction may become slow and rate controlling in calcium release.

[In passing notice that the probable role of the intestinal binding protein, now called calbindin, is just to accelerate the diffusion of calcium in the cell while that of parvalbumin is to remove calcium so as to give faster relaxation in very fast muscle cells. Both proteins are dynamic controls.]

\section{Calmodulin Connections - Kinases}

The calcium/calmodulin trigger activates kinases. In this essay interest centres on the internal mobility of the kinase which is altered by calcium via calmodulin so that the catalytic activity is no longer in abeyance. The hinge motion of kinases $(2,29,33,43)$ as revealed by both NMR and crystallographic studies of phosphoglycerate kinase is seen, Figure 7 , to rest upon the motion of helices between two $\beta$-sheet domains, both of which bind one of the two substrates. Activity relies upon the closing of the gap between the opposed substrate sites. We can readily appreciate that the binding of a protein (calmodulin without calcium) to this helical hinge region could prevent activity just as the binding of drugs to the helices of calmodulins alters its potential for structural change. The addition of calcium to the calmodulin could then be supposed to release the constraint on gap closure. The mobile connection between sets of helices in the same or different polypeptide chains is becoming more apparent as helical structures are being found in membranes and elsewhere where one region of a protein controls the activity of another, Table X. An alternative mode of dynamic action is for the calmodulin to bind to a swinging inhibitor arm of a kinase segment. Both modes of action may well be present in different kinases.

Table X. Helix/helix connections in biological devices

\begin{tabular}{|c|c|}
\hline Device & Functional components \\
\hline Kinase switch & Calcium/calmodulin/kinase \\
\hline ATP-synthesis & Protons/peptide C/ATP-ase \\
\hline Repression & Repressor/DNA \\
\hline Proton gradients & Channel/oxidase, $\mathrm{Cyt} b / f$ particle \\
\hline Reaction centres & $\begin{array}{l}\text { Non-heme Fe/Quinone oxido- } \\
\text { reductases }\end{array}$ \\
\hline $\mathrm{O}_{2}$-carriers & $\begin{array}{l}\text { Haemoglobin, Haemocyanin } \\
\text { allosteric response }\end{array}$ \\
\hline
\end{tabular}

\section{Zinc and Calcium Regulatory Proteins}

The levels of calcium in a cell are controlled in part by calmodulin-like proteins and in part 


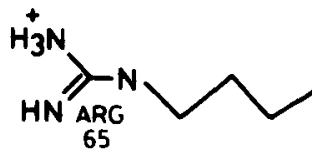

\section{C-DOMAIN}
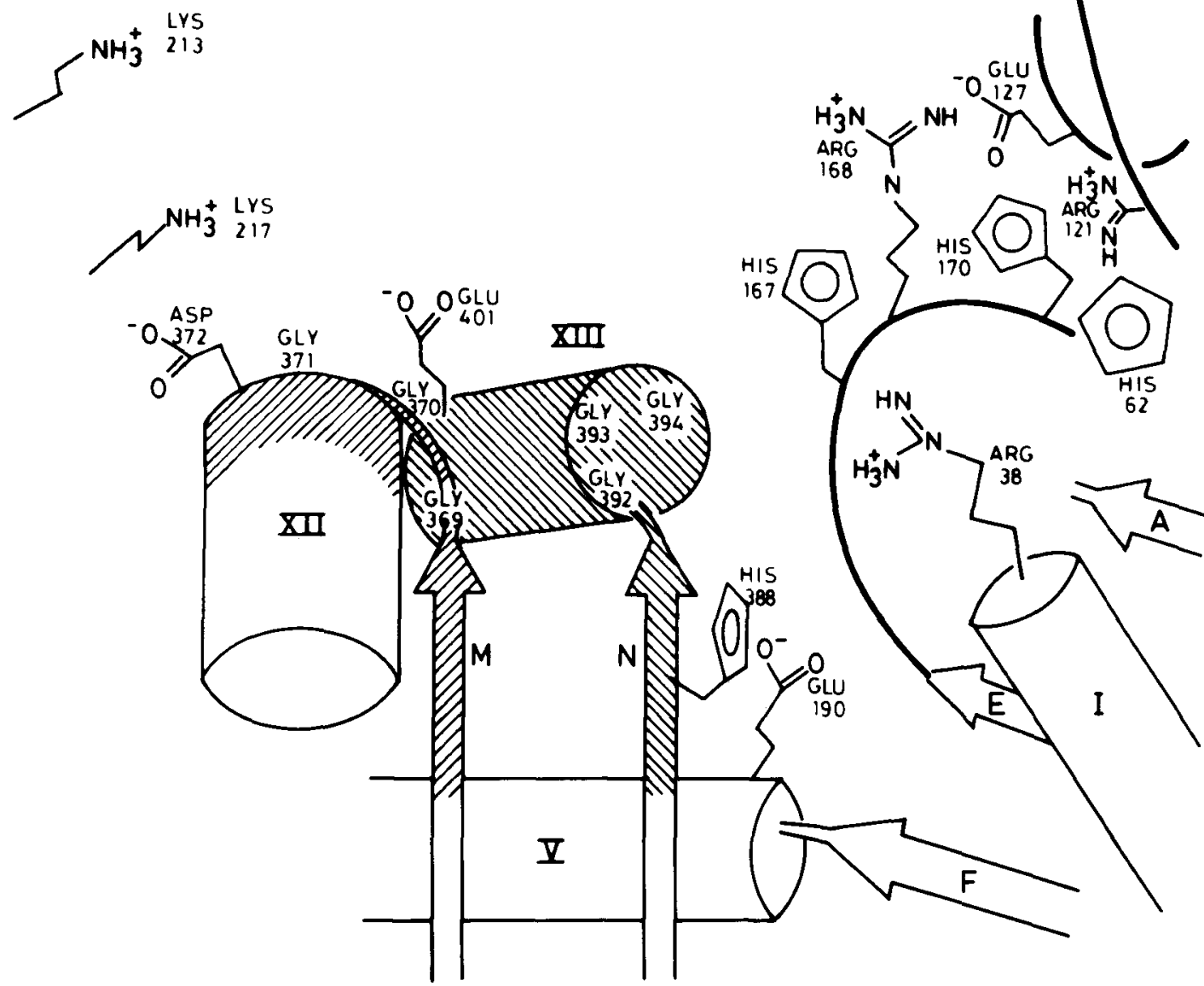

Figure 7a. The postulated hinge of phosphoglycerate kinase. Two large $\beta$-sheet domains $(\mathrm{N}$ - and $-\mathrm{C}$ ) move through the relative rotational/translational motions of two helices. Each domain face carries a substrate. Note the highly charged surfaces for fast reactions (after Drs. C. BLAKE and H. WATSON).

by pumps. The calcium ATP-ase pump has a sequence which shows that it is not an EF-hand protein and although the calcium site is not known it looks as if it is at a set of sequential carboxylates as shown by GreEN and his colleagues (15). Somewhat speculatively we may suggest that this is a poorly structured region of the protein until calcium binds. After calcium- binding the protein must change conformation once, and once more on ATP hydrolysis, so as to force the calcium out of the cell actually reducing the binding constant from $\log K=7$ to $\log$ $K=2.5$. It is an essential feature of the protein that it should have many states and respond rapidly (milliseconds).

Zinc levels in cells are controlled by buffering 


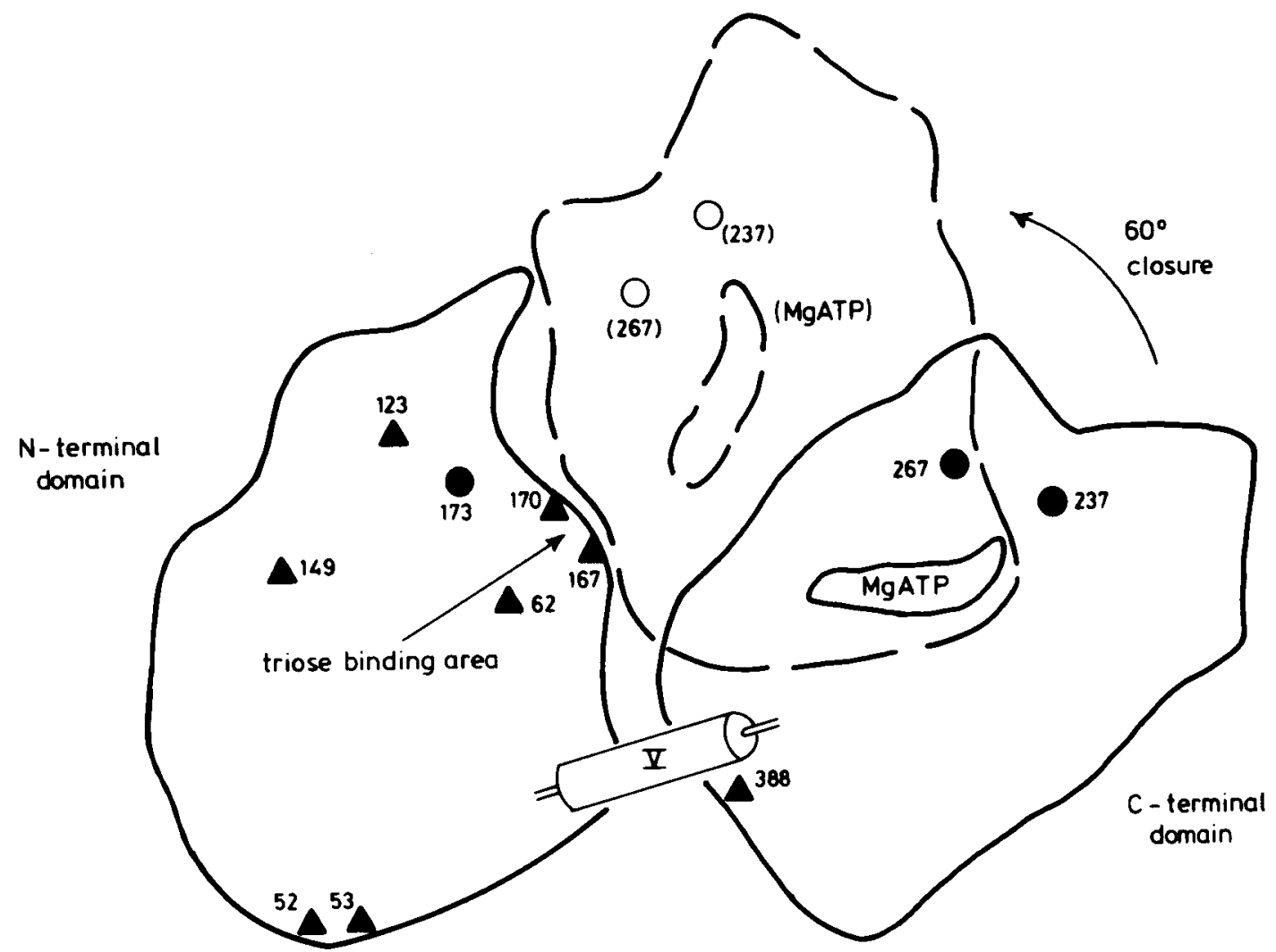

Figure $7 \mathrm{~b}$. An explicit representation of a kinase closing movement about a hinge helix $\mathrm{V}$ and the histidine residues which have allowed us to make a full study of the dynamics by NMR. [I am indebted to Drs. C. BLAKE and H. WATSON for much discussion relating to Figure 7]. The connection of a kinase to calmodulin would be through the calmodulin helices and region iv (see Figure 6) to the kinase hinge.

in the cell equivalent to the supposed action of parvalbumin on calcium. The protein responsible is metallothionine. Interestingly, it is a random coil, a totally dynamic protein, which binds zinc through thiolate groups with a binding constant of about $\log \mathrm{K} \simeq 10(\mathrm{pH}=7)$ while forming a well-defined structure. Random coil proteins have their value in speed of adjustment, but selectivity is inevitably reduced and this protein binds many heavy metals - in this case actually increasing its value to the removal of cytoplasmic copper and cadmium. The off-rate is modest, seconds to minutes, but then zinc is more like a hormone while calcium is like a transmitter.

The zinc metallothionine speaks indirectly to DNA and thence to the production of metallo- thionine and other proteins and thereby controls the levels of free zinc and protects from intracellular cadmium and copper. The other functions of this zinc protein are not known, but in the copper form it is pumped out of cells. The overall handling of zinc in cells awaits a burst of research similar to that concerning calcium in the last twenty years.

\section{Slower Metal Ion Control}

Now so far we have been concerned with rapid binding and release of metal ions so as to pulse a system. A more sustained effect requires a slow release. Clearly, this could come about through internal rate processes of a calcium (zinc) binding peptide which actually controlled the $k_{b}$ rate constant. We can illustrate how the slow dynam- 


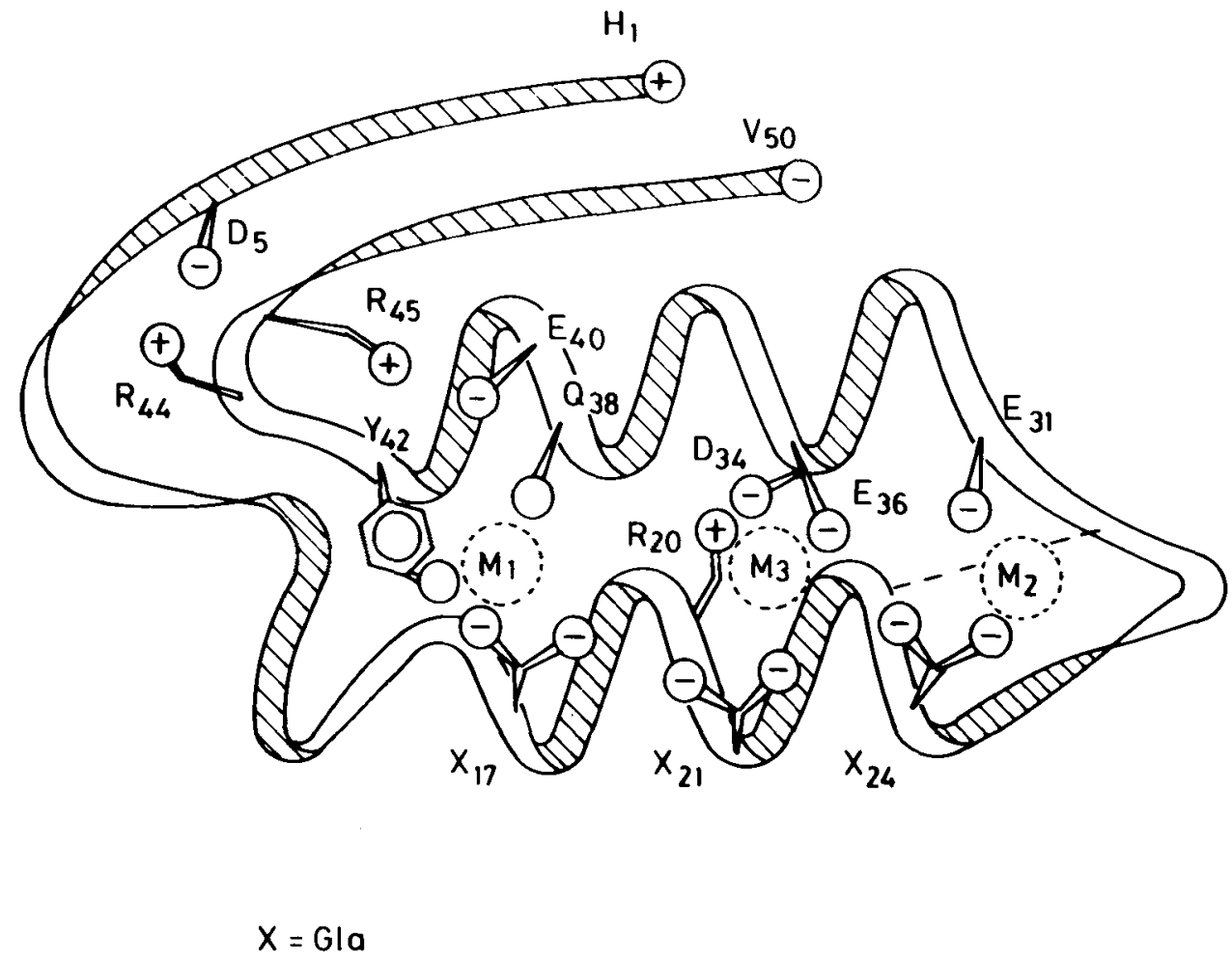

Figure 8. The structure of calcium-bound osteocalcin as given first by HAUSKA and CARR (16) and confirmed by us using NMR data. $M_{1}, M_{2}, M_{3}$ are calcium binding areas. Its slow relaxation is described in the text. Notice the extreme charged nature of the surface and the separation of positive and negative centres. The broken line is the -S-S- bridge.

ics of such a system, calcium plus peptide, may well operate by reference to our study of an extracellular peptide, the Gla-containing osteocalcin which binds to bone - presumably the phosphate of bone. There is a parallel tight binding of calcium to the blood-clotting Glacontaining protein, prothrombin. The parallel is striking in that both peptides containing an -S-Sbridged loop which also contains proline. We believe that slow controls in prokaryotic cells will also be uncovered using $\mathrm{Fe}$ (II) and $\mathrm{Mn}$ (II) ions.

\section{Calcium and -S-S- Cross-links in Peptides}

The value of calcium cross-links in controlling mobility in peptides can be seen in osteocalcin. Our NMR (23) studies and the work of HAUSCHKA and CARR (16) show that the peptide shows very little evidence for other than random structure in the absence of calcium, except in the region of a seven membered Cys-Cys sequence. In the presence of calcium there is generated a pair of helical segments on either side of the loop and a strong interaction between two aromatic residues one from each loop, Figure 8. The structure is shown to be in slow exchange by the restricted flipping rotation of a tyrosine ring on one helix, Figure 8 , which is locked to another. The two helices which are formed on binding the calcium are cross-linked by the metal ion through Gla and other carboxylate carrying residues and the whole is also connected to the dynamics of the proline in the loop, Figure 8. The calcium ion plus the -S-Sbridge clearly will now protect this peptide from peptidases. (A parallel protection is seen in 
phospholipase A.2). In fact, the binding constant for calcium is such, $\mathrm{K}=10^{4} \mathrm{M}^{-1}$, that osteocalcin is effectively always calcium bound. It may well be that this same calcium forms the initial binding to the phosphate of bone apatite to which the peptide binds with very high affinity. Only a little imagination is required in order to link this description to that of calcium action in the blood-clotting cascade, where the calcium cross-links the prothrombin Gla unit to the membrane phosphate. Here calcium acts in cooperation with the kringle peptides to control triggering. It can well be that the calcium action is sustained by the slow exchange of the peptide conformation and that calcium protects proteins by cross-linking and preventing protease attack, see p. 5. We have already referred to the multitude of -S-S- bridges in these proteins.

The rates at which calcium enters and leaves a system are clearly becoming increasingly sophisticated. The degree of sophistication appears to go one level higher in the activation of protein kinase C. Here hormonal action releases inositol phosphates and fatty-acid esters. The former release calcium while the latter bind to the kinase such that it can be triggered by calcium in a sustained binding. In other words, normal calcium influx from extracellular stores through a channel has no effect on kinase $\mathrm{C}$, but kinase $\mathrm{C}$ is switched on by vesicular calcium only after a nominally weak $\mathrm{Ca}^{2+}$ site associated with the kinase (on/off reactions very fast) has been converted to a strong one by the fatty acid esters. While on-rates remain fast the off-rate of calcium can be slow depending upon the calcium binding constant. If $\mathrm{K}=10^{9} \mathrm{M}^{-1}$ the pulse lasts one second, not the $10^{-3} \mathrm{sec}$ of muscle contraction.

\section{Proline-Residues (An Aside)}

The importance of proline in the structure of proteins has been stressed for some time. The dynamics of proline conformation have often been discussed too in the description of slow steps in protein folding. Here I wish to stress the role of proline in the control of dynamics of activities. The first example is in stiffening single chain peptides which are part of hinged rods (1, $12,26)$. The second is in the flipping between conformations, cis/trans, which can be used to control the rate of changes in structure and even the release of metal ions. The cases which need most careful attention are those where the proline lies in a short loop between two cysteines of a bridge in such examples as those which involve calcium triggering or controls in extracellular solutions. The third is in the helical membrane peptides, but the function is not known. Perhaps we could liken proline to magnesium and glycine to calcium.

\section{Zinc as a Cross-bridge}

Outside cells protein stability is assisted by -S-S- bridges and calcium cross-linked chelation. Inside cells neither mode is satisfactory, although both are known in rare examples, since the -S-S- link suffers reduction and the calcium ion concentration is very low, removing or weakening reversible binding. Alternative crosslinks inside cells could use $\mathbf{M g}^{2+}$ - known to be a poor cross-linking agent in chemistry, but probably functional in the proton ATP synthetases - or $\mathrm{Zn}^{2+}$. Zinc clearly acts as a weak cross-link in insulin, where calcium may also be important, while the $\mathrm{Zn}^{2+}$ cross-link in aspartate transcarbamylase and alcohol dehydrogenase is clearly much more powerful. The major feature of this cross-link between four thiolates of cysteines is that while it is strong it is still fluctional. In this sense it resembles calcium extracellular cross-links and not so much -S-S- cross-links. The presence of both metal ions as cross-links is a great limitation on translational mobility, but both allow swivelling motions around them as in a ball and socket joint. It is interesting to speculate here on the roles of zinc and calcium in the stress/strain properties of fibres such as various polysaccharides and keratins.

\section{Zinc as a Catalyst (An Aside) $(30,31,40)$}

A short note here on the role of zinc as a catalyst is in order since it illustrates the way in which selectivity is increased in more rigid systems. I shall do this by using a set of statements.

(a) Zinc sites when catalytic are associated with $\beta$-sheet protein structures not helices, contrast isulin and S-100 with carbonic anhydrase. 
(b) Zinc sites when catalytic are strained (entatic) and are (highly) selective for zinc, see ref. 30 .

(c) The residual mobility of zinc is very useful in catalysis.

(d) Exchange from the site is not permitted by the protein folding rates. The proteins are $\beta$ sheet.

The contrast between only a small degree of motion within a metallo-protein and those metal protein complexes which show fast exchange is reflected in function. I refer to a review which extends these statements (40).

While noting the value of zinc as an attacking group notice should also be taken of the substrates of many of its enzymes. In this article the function of zinc in the proteases which release hormonal peptides is particularly interesting. It would take a lengthy article to attempt to link the interwoven controls of zinc proteases and hormone release and yet another to describe the connection of the calcium controlled proteases to quite different hydrolyses in extracellular digestion, blood-clotting and with the intra-cellular proteases triggered perhaps to accelerate cell destruction. The intricacies of biological signalling are numerous, but note that speed of action is especially associated with calcium and zinc ions.

[It is interesting to examine the generalisation that all enzymes are based on $\beta$-sheet linked binding sites for substrates rather than on $\alpha$-helical proteins (41). This would allow tight control over selectivity since mobility is low. The overwhelming majority of enzymes obey this rule, but there are illuminating exceptions. Heme-enzymes are usually largely based on helical structures, but here of course relative rigidity when required is maintained by the cross-linking of the enzyme to the iron and often through thio-ether links as well as through the strength imposed by the porphyrin ring - a sheet in itself. Another odd example is citrate synthetase, but here the largely helical enzyme has a large cleft opening and closing reaction presumably to keep out water. We then make a rider to the above rule. Enzymes which require cleft openings or closings will be built upon helices at least in part in order to generate the dynamic properties required. Cytochrome $\mathrm{P}-450$ and en- zymes with controlled order of substrate binding are likely to be partly helical].

\section{Highly Charged Peptides (6)}

I do not wish to close without reference to extreme mobility and relatively poor specificity. Amongst cations sodium and potassium are quite generally active in binding to biological molecules at on-rates of $10^{10} \mathrm{sec}^{-1}$ and off-rates greater than $10^{8} \mathrm{sec}^{-1}$ so causing no reasonable "memory effect", i.e. there is no storage of chemical change, but only electrical switching. They have a dynamic statistical distribution around all open poly-electrolytes. However, there are also in biology a diversity of larger highly charged poly-amines and proteins which are also attracted to negative poly-electrolytes. Interest in this article concerns only to a secondary degree the selective competition between all these cations (28). Of greater interest is their mobility along one or two dimensional net-works. Seemingly these charged bodies, and we should also notice calcium ions again as well as membrane proteins such as cytochrome $c$, float along the surfaces as if they saw no potential energy minima $(35,39)$. (The parallel in extremus is with electrons in metals). This type of dynamics is of the greatest use in the control over diffusion kinetics. Perhaps we should suspect that the more electrostatic the interaction the more likely it is that the interaction will be of low selectivity and very high conformational mobility. This contrasts with the use of hydrophobic surfaces, e.g. using tryptophan side chains as discussed earlier, where mobility is frozen on combination, see p. 5 to 6 , for a discussion of these different cases.

In the extreme parts of surfaces of water soluble proteins all of which will be assumed to be dynamic structures could therefore be considered to belong to four classes:

(a) Convex and hydrophilic - cytochrome-c, see Figures 9 and 10.

(b) Convex and more hydrophobic - neurotoxin, Figure 1.

(c) Concave and hydrophilic - calmodulin $\mathrm{Ca}^{2+}$ site, Figures 5 and 6.

(d) Concave and hydrophobic - kringle site, Figure 4. 


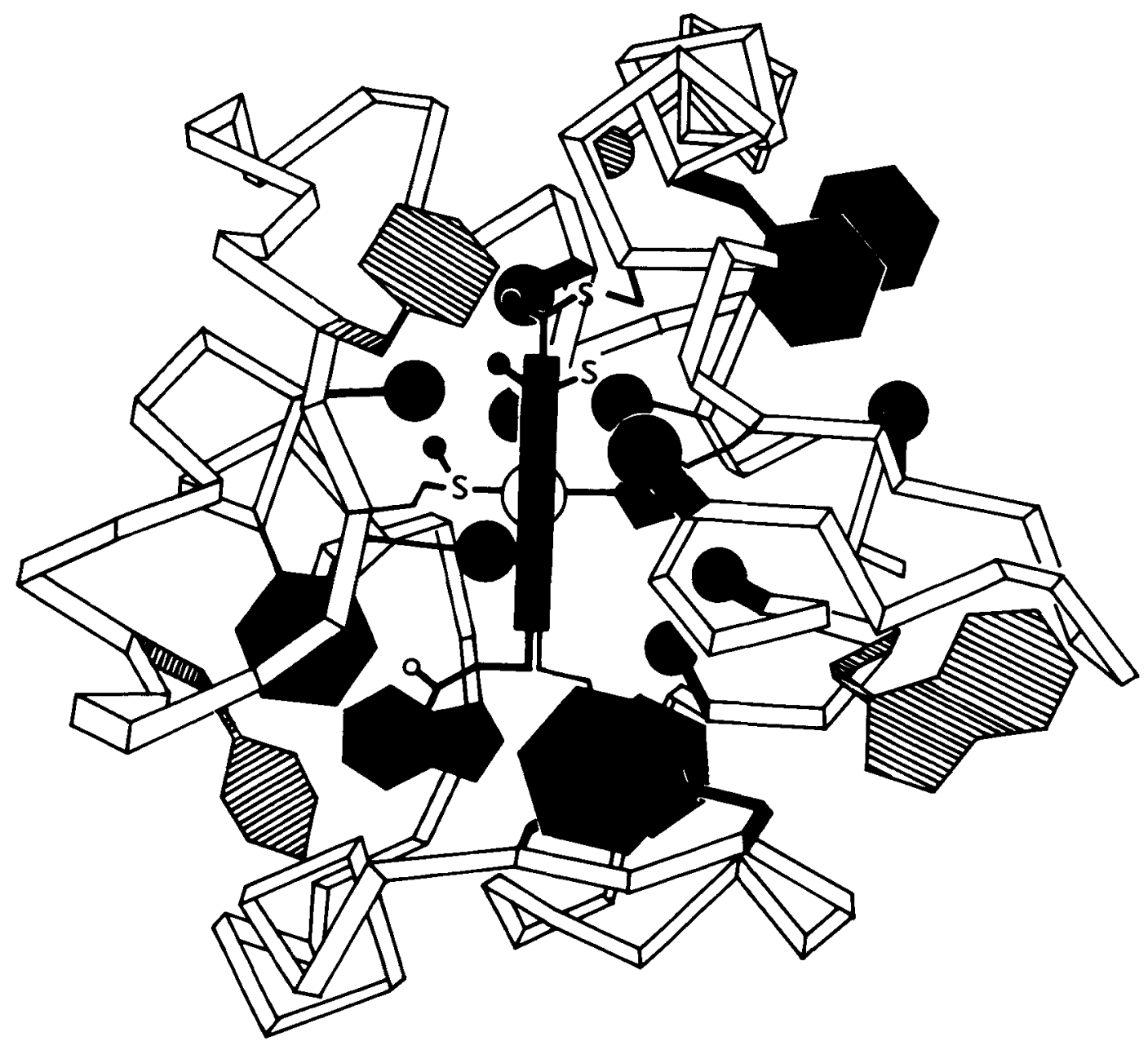

Figure 9. A mobility map of cytochrome $c$ from NMR data showing the rates of movement of internal and external residues in this tightly folded enzyme. Hatched residues have high flip rates, filled-in side-chains have very low flip rates. The core is tightly packed except around conserved Phe-82. The back-bone shows little motion and the tight packing of aromatic side-chains is a constraint on helix/helix motion. Contrast calmodulin.

We must add to this hidden mobile segments which are part of the surface for only a small part of the time and which we have considered to be of considerable importance for antigenicity or destructive hydrolysis. The functions of these different zones can be very different in the way in which they are used in mobile, hand-in-glove, or in static, die-in-mould, organisation of proteins (or polysaccharides and polynucleotides). It may be that fast electrostatic (very mobile contacts) generally precede slow hydro- phobic closely knit fittings in which case the latter will not be used in systems which need to relax quickly.

\section{The Relay of Information through the Cell} Membrane (10)

The agonist molecules whether they be hormones or transmitters bind to the outer surfaces of cells at receptors. The question arises as to how knowledge of this binding can affect the 


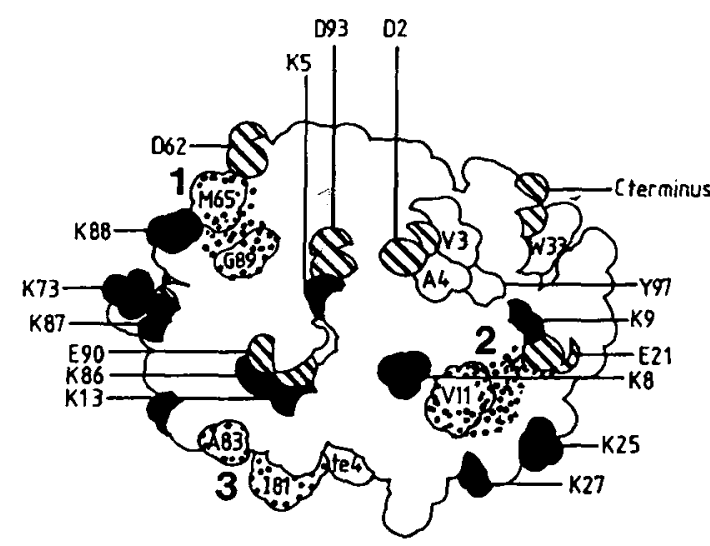

TOP

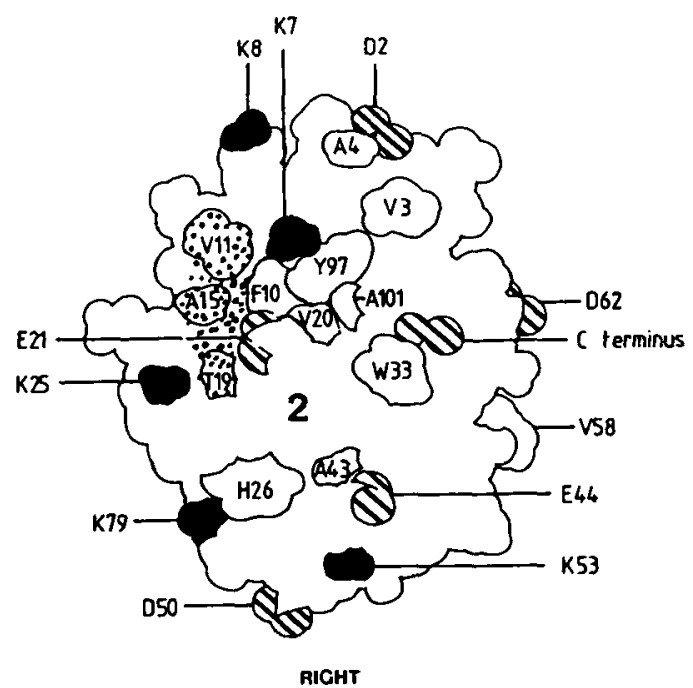

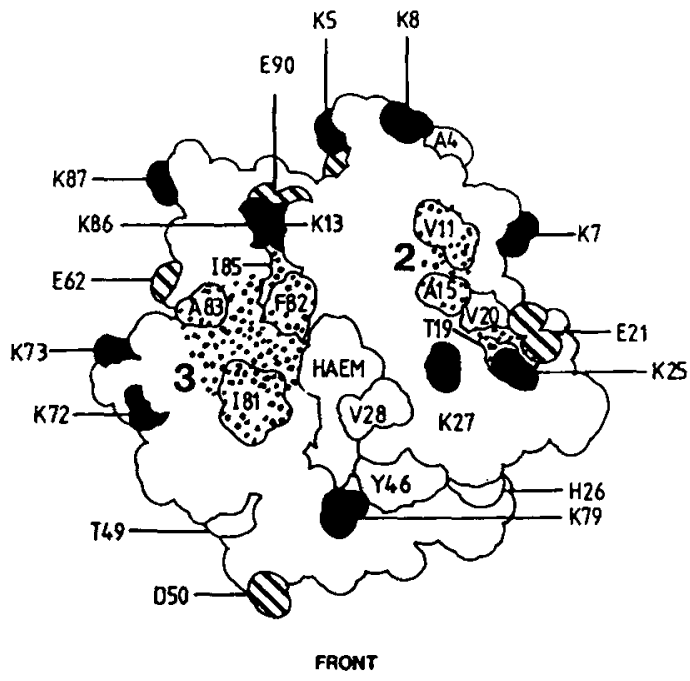

Figure 10. The binding to $\left[\mathrm{Cr}(\mathrm{CN})_{6}\right]^{3-}$ to cytochrome $c$ from NMR data. There are many sites (stipled) at positively charged groups (filled in) and away from hatched negative charges. Probably the anion runs over this convex surface which is extremely mobile.

internal mechanisms of cells. This consideration allows me to put together many of the separate sections of this article, Table XI. A receptor such as the EGF-receptor appears to have but a single helical connecting protein rod through the membrane to the interior kinase. The most obvious transmission system would then appear to be a simple push/pull on the helix which may be accompanied by a rotation. It is then simple to imagine that the binding of the EGF-molecule to the receptor can bring about a conformational change on one side of a membrane which is relayed to a conformational change, a switch-on, on the other side. The strength of the push/pull or the rotation of the helix will be a measure of the exact conformation change i.e. the structural change in the receptor on binding EGF, since the EGF-molecule is taken to be rigid. The transmitted change across the membrane has then some precise relationship to the first structural adjustment. Degrees of agonist and antagonist behaviour reflect degrees of conformational 
Table XI. Combined uses of metal ions, small organic molecules and peptides

\begin{tabular}{ll}
\hline $\begin{array}{l}\text { System } \\
\begin{array}{l}\text { Blood clotting and } \\
\text { clot removal }\end{array}\end{array}$ & Agents used \\
$\begin{array}{l}\text { Cormonal } \\
\text { regulation }\end{array}$ & $\begin{array}{l}\text { Calcium, membrane, kringles } \\
\text { c-AMP, long chain acyl glyce- } \\
\text { rides, membrane kinase C, EGF }\end{array}$ \\
$\begin{array}{l}\text { Muscle } \\
\text { concentration }\end{array}$ & $\begin{array}{l}\text { Calcium, c-AMP, filaments, } \\
\text { calmodulin (N.B. adrenaline) }\end{array}$ \\
Visual perception & $\begin{array}{l}\text { Calcium, GTP, channels, mem- } \\
\text { branes }\end{array}$ \\
Fertilisation & $\begin{array}{l}\text { Calcium, zinc, vesicles, kinases, } \\
\text { filaments } \\
\text { (Na, K) calcium, acetyl choline, }\end{array}$ \\
(synapse & adrenaline etc. membranes \\
\hline
\end{tabular}

change at an ion channel or at the internal kinase which in turn control rates of the enzyme reaction.

The scheme which we must follow is:

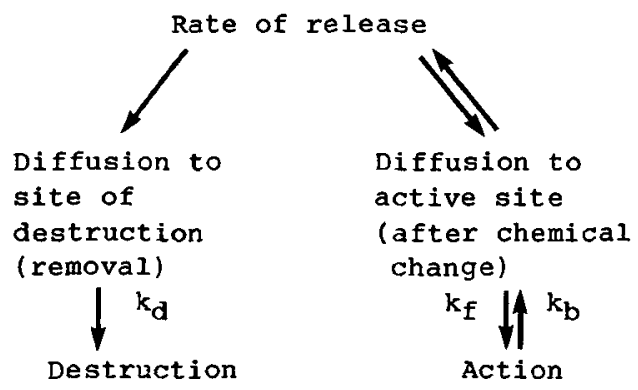

The diffusion rates are controlled partly by the location of release, destruction (pump) and action sitès. The diffusion causes dilution as well. Since the molecules described here are all small the diffusion rate is fixed unless a two or one dimensional diffusion surface is provided. (Note, however, the use of calbindin p. 19). The rate constants $k_{f}, k_{b}$, and $k_{d}$ are controlled by mobility (internal diffusion) and fitting parameters. The time constants for diffusion are around $10^{-10} \mathrm{sec}$, but it takes considerable time to diffuse in a selected direction, e.g. seconds or minutes in the human body. The other rate constants are arranged so that the action can be sustained for
Table XII. A somewhat speculative description of the space/time factors involved in hormone action and destruction

\begin{tabular}{llc}
\hline $\begin{array}{l}\text { Transmitter } \\
\text { (hormone) }\end{array}$ & $\begin{array}{l}\text { Diffusion } \\
\text { distance }\end{array}$ & $\begin{array}{r}\text { Time constant } \\
\text { scale (secs) }\end{array}$ \\
\hline Acetylcholine & short & $10^{-3}$ \\
Calcium & short & $10^{-3}$ \\
Adrenaline (brain) & short & $10^{-3}$ \\
Brain peptides & short & $10^{-2}(?)$ \\
Adrenaline (blood) & medium (long) & $10^{2}$ \\
Kringle & medium & $10^{2}$ \\
Insulin & longish & $10^{4}$ \\
Sterols & long & $10^{5}$ \\
Protease inhibitors & long & $10^{5}$ \\
Neurotoxins & long & $10^{5}$ \\
Thyroxines & long & $10^{5}$ \\
\hline
\end{tabular}

different periods of time: hours, days, minutes or milliseconds, Table XII attempts to give an impression of this view.

\section{Conclusions:}

\section{(a) Smaller Molecules}

I have tried to show that it is essential to follow Linderstrøm-Lang on the track of dynamics in the overall pattern of activity

Composition (Sequence): Structure : Dynamics : Function

I have illustrated the theme with examples of some peptides and some metal ions mainly in the agonist/receptor relationship. However, the discussion is readily extended to proteins and especially domains of proteins and to small organic molecules (drugs). Highly mobile proteins exist, e.g. chromagranin A, as do relatively mobile proteins, e.g. histones, as do relatively rigid domains, enzyme active sites. The transition from random to rigid conformation is gradual and carries with it changing functional potential from relatively precise matching (enzymes), to control responses (calmodulins and histones), to configurational entropy switches (sol $\rightleftarrows$ gel) of glycoproteins. The gradation follows the change in cross-linking from more or less rigid $\beta$-sheets ( $\mathrm{H}$-bonds) and -S-S-bridges to 
packed helices (hydrophobic cross-bridges) to random proteins. Metal ions especially calcium and zinc give an added wide variety of possibilities from inorganic chemistry.

\section{(b) Larger Proteins}

While I have firstly drawn attention to the differential mobilities in different peptides the description of the functional value of mobility has secondly been extended to larger proteins where it has been valuable to pay attention to segmental rather than general mobility. Examples included the kinases where mobility is not found in the $\beta$-sheet framework of the binding sites of their substrates, but in a multi-helical segment lying between them. Another type of mobile segment was the linker region outside domains of blood-clotting proteins which allows domains of prothrombin (kringles), plasminogen (kringles) and fibronectin (fingers) to act in a localised but flexible manner with respect to one another. Now we should remember the properties of the domains which are connected by the more mobile segments.

Apart from the domains the interesting mobility is on the convex (more) and concave (less) surfaces of larger proteins. We expect the concave surfaces or grooves to be of restricted mobility and they often form enzyme active sites. The exposed convex surfaces are mobile and this mobility may well allow very flexible interaction with other proteins, membranes (cytochrome $c$ ) or DNA (histones) so that partners flow relative to one another without dissociation. Here we expect electrostatic rather than hydrophobic contact areas.

When all these features are put together in a cooperative assembly plus an energy source we have the basic constituents of a molecular machine with moving parts and framework structures. However, everything I have described is reversible motion - dynamic structure. When connected to external energy it becomes a flow dissipative structure, and I wish to hazard a final opinion about flow.

\section{(c) Flow Structure}

A lecture such as this allows certain very speculative remarks. I have said that flow-structure not dynamic structure is the essence of biology and I have related it to the flow of the structure of our planetary system, but I have avoided it in this article. In fact, it is directly related to the flow of our planetary system, since this system is the source of biology's energy. This means that at the heart of biology there must be a molecule which has only flow-structure and in turn this molecule must be DNA and that it is linked to the time frame of the universe. We conclude then that DNA never passes through exactly the same conformational state twice - it is always developing. In this regard, the appreciation of the dynamics of the structure of the cell nucleus require a quite separate essay and another time scale. Whatever the nature of life is it can be traced back to the energetics of the big bang.

I close reminding my reader of the originality of LINDERSTRøM-LANG's views while thanking the donors of this award for permitting me to illustrate the direction in which his type of thinking is leading us.

\section{REFERENCES}

1. Bhandari, D. G., B. A. Levine, I. P. Trayer \& M. E. YEADON: An NMR study of mobility and conformational constraints of myosin light chains. Europ. J. Biochem. 160, 349-356 (1986)

2. Blake. C. C. F. \& D. W. Rice: Phosphoglycerate kinase. Phil. Trans. Roy. Soc. (London) B, B293, 93-104 (1981)

3. Blake. C. C. F., D. E. P. Grace, L. N. Johnson, S. J. Perkins, D. C. Philllips, R. Cassells, C. M. Dobson, F. M. Poulson \& R. J. P. Williams: Physical and chemical properties of lysosyme. Ciba Foundation Symposium 60, 137-185 (1978)

4. Brown, L. R., W. Braun, C. Boesch, K. H. LeE, G. WIDER \& K. WÜthrich: Sequence assigments of individual resonances in proteins. Biopolymers 22, 131-138 (1983)

5. CAMPBell. I. D.. C. M. Dobson \& R. J. P. Williams: The study of the conformational states of proteins by nuclear magnetic resonance. Biochem. J. 231, 1-10 (1985)

6. CoOkson, D. J., B. A. Levine, R. J. P. Williams, M. JoNTEll. A. LindE \& B. DE BERnARD: Cation-binding by rat-incisor-dentine phosphoprotein. Europ. J. Biochem. 110, 273-282 (1980)

7. Dalgarno, D., R. E. Klevit, B. A. Levine \& R. J. P. WILliams: The calcium receptor and trigger. Trends in Pharmacological Sciences 5, 28-36 (1984) 
8. Dodson, G., R. Hubbard \& C. ReYnolds: The anatomy of insulin. Recent Adv. Diabetes 1, 19-25 (1984)

9. Dyson, H. J., K. J. Cross, R. A. Houghton, I. A. WILSON, P. E. WRIGHT \& R. A. LERNER: The immunodominant site of a synthetic immunogen has a conformational preference in water for a type II reverse turn. Nature 318, 480-483 (1985)

10. Egmond, M. R., R. J.P. Williams, E. J. Welsh \& D. A. REES: NMR studies on glycophorin and its carbohydrate-containing tryptic peptides. Europ. J. Biochem. 97, 73-83 (1979)

11. Esnouf, P., M. P. Lawrence, B. C. Mabbutt, L. Patthy, N. D. Pluck \& R. J. P. Williams: The outline structure of protein domains called kringles. Bull. Soc. Chim. Belg. 94, 883-896(1985)

12. Evans, J. S., B. A. LeVINe, I. P. Trayer, C. J. Dorman \&C.F. Higgins: Sequence-imposed structural constraints in the ton B protein of E. coli. FEBS Lett. 208, 211-216 (1986)

13. FOX, R. O.\& F. M. RICHARDS: A voltage gated ion channel model inferred from the crystal structure of alamenthicin at $1.5 \AA$ resolution. Nature 300 , 325-330 (1982)

14. GURD, F.R.N.\& M. ROTHGEB: Motions in proteins. Adv. Protein Chemistry 33, 73-165 (1979)

15. Green, N. M., W. R. Taylor, C. BrandL, B. KorCZAK \& D. M. MACLENNAN: Structural and mechanistic implications of the amino-acid sequence of calcium-transporting ATP-ases. Ciba Foundation Symposium 122, 93-107 (1986)

16. HausChKa, P. V.\&S. A. CARR: Calcium-dependent $a$-helical structure in osteocalcin. Biochemistry 21 , 2538 (1982)

17. Hider, R. C., A. F. DRake, F. Inagaki, R. J. P. Williams, T. Endo \& T. MiYazaWa: Molecular conformation of $\alpha$-cobratoxin as studied by nuclear magnetic resonance and circular dichroism. J. Mol. Biol. 158, 275-291 (1982)

18. INAGAKI, F., J. BOYD, I. D. CAMPBELL, N. J.CLAYDEN, W. E. Hull, N. TamiYa \& R. J. P. Williams: Dynamics of erabutoxin $b$ as studied by nuclear magnetic resonance. Europ. J. Biochem. 121, 609$616(1982)$

19. Inagaki, F., T. Miyazawa \& R. J. P. Williams: The dynamic structures of proteins: Short and long neurotoxins as examples. Bioscience Reports 1, 743-755 (1981)

20. Kimball, M. R., A. Sato, J. S. Richardson, L. S. ROSEN \& B. W. LOW: Molecular conformation of erabutoxin b. Biochem. Biophys. Res. Commun. 88, 950-959 (1979)

21. Krieger, D. T., M. J. Brownstein \& J. B. Martin: "Brain Peptides". J. Wiley and Sons, New York (1984)
22. LeVine, B. A., D. L. RABenSTEIN, D. SMYTH \& R. J.P. WILliams: NMR studies of enkephalin. Biochim. Biophys. Acta 579, 279-290 (1979)

23. Levine, B. A., R. Meats \& R. J. P. Williams: The structure of osteochalin in calcium bound and calcium free states. (To be published)

24. Linderstrøm-Lang, K. \& J. A. Schellman: Protein structure and enzyme activity. In: The Enzymes. (2nd Ed. P. D. Boyer ed. ), Academic Press, New York, Vol I, p. 443-510 (1959)

25. PARK. C. H. \& A TUlinsky: Three dimensional structure of the kringle sequence: Structure of prothrombin fragment 1 . Biochemistry 25, 39773982 (1986)

26. Packman, L. C., G. Hale \& R. N. Perham: Repeating functional domains in the pyruvate dehydrogenase multi-enzyme complex. EMBO J. 3, 13151319 (1984)

27. RICHARDS, F. M.: Packing defects, cavities, volume fluctuations, and access to the interior of proteins, including some general remarks on surface area and protein structure. Carlsberg Res. Commun. 44, 47-63 (1979)

28. TAM, S. C. \& R. J. P. Williams: The electrostatic interaction between organic ions. J. Chem. Soc. Faraday Trans I, 80, 2255-2267 (1984)

29. TANSWELl, P., E. W. Westhead \& R. J. P. WILliams: Nuclear magnetic resonance study of the activesite structure of yeast phosphoglycerate kinase. Europ. J. Biochem. 63, 249-262 (1976)

30. VALleE, B.L.\& R.J.P. Williams: Metallo-enzymes: The entatic nature of their active sites. Proc. Natl. Acad. (USA) 59, 498 (1968)

31. VALLEE, B. L.: Zinc and other active site metals as probes of local conformation and function of enzymes. Carlsberg Res. Commun. 45, 423-441 (1980)

32. VOGEL, H.\& F. JAHNIG: The structure of melittin in membranes. Europ. J. Biochem. (1987) to be published

33. Watson, H. C., P. J. Shaw, T. N. Bryant, N. J. Walker, P. L. Wendell, L. A. Fothergill, R. PERKINS\& S.C. CONROY: Sequence and structure of yeast phosphoglycerate kinase. The EMBO J. 1, 1635-1640 (1982)

34. Westhof, E., D. Altschunk, D. Morar, A. C. Bloomer, A. Mondragon, A. KluG, \& M. H. V. VAN REGENMOTEL: Correlation between segmental mobility and the location of antigenic determinants in proteins. Nature 311, 123-126 (1984)

35. Williams, G., N. J. Clayden, G. R. MoORE \& R. J.P. WILLIAMS: The structure of cytochrome $c$ in solution. J. Mol. Biol. 182, 409-428 (1985)

36. Williams, R. J. P.: The functions of chains of catalysts. J. Theor. Biol. 1, 1-13 (1961) 
37. Williams, R. J. P.: The conformational states of proteins in solution. Biol. Rev. 54, 389-437 (1979)

38. Williams, R. J. P. and others: In: Calcium and The Cell. Ciba Foundation Symposium No. 122 (D. Evered \& J. Whelan ed. ), J. Wiley \& Sons, Chichester (1986)

39. Williams, R. J. P., G. R. Moore \& G. Williams: Understanding the surfaces of proteins. In: Progress in Bio Organic Chemistry and Molecular Biology. Y. A. Ovchinnikov ed., Elsevier, New York pp. 31-39 (1984)

40. WiLliams, R. J. P.: Zinc - what is its role in biology? Endeavour (New Series) 8, 40 (1984)

41. Williams, R. J.P.: The symbiosis of metal ion and protein function. Eur. J. Biochem. 150, 231-248 (1985)

Accepted by H. KLENOW
42. Williams, R. J. P. \& G. R. Moore: Protein antigenicity, organisation and mobility. Trends Biochem. Sci. 10, 96-97 (1985)

43. WiLliams, R. J.P.: The connections between particle flow and mechanical, electrical and chemical work. J. Theor. Biol. 121, 1-22 (1986)

44. Williams, R. J. P., P. EsNouf, M. LAWRenCE \& A.C. SEDERKOM-WILliaMS: The similarities and differences in structures between kringle 1 of prothrombin and kringle 4 of plasminogen. FEBS Lett. 209, 111-116 (1986)

45. WUTHRICH, K, \& G. WAGNER: Internal motions in globular proteins. Trends Biochem. Sci. 3, 227-230 (1978)

46. WÜTHRICH, K: NMR studies of motions in proteins. Biochem. Soc. Symp. 46, 17-37 (1981) 